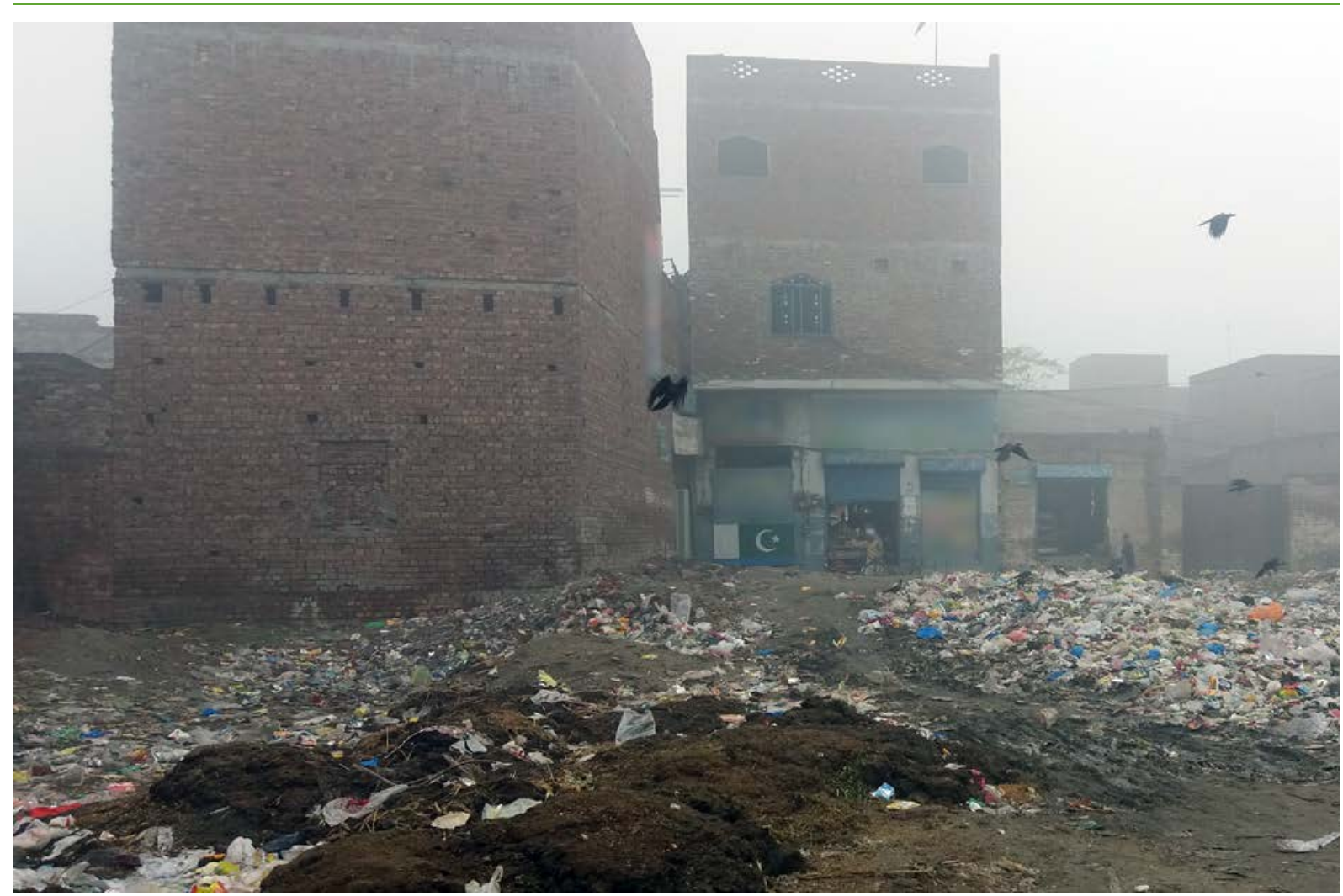

A low-fee private school in a slum area in Punjab, Pakistan. Photo: Momina Afridi.

\title{
EQUITY AND QUALITY IN AN EDUCATION PUBLIC-PRIVATE PARTNERSHIP \\ A study of the World Bank-supported PPP in Punjab, Pakistan
}

DR. MOMINAAFRIDI

Oxfam Research Reports are written to share research results, to contribute to public debate and to invite feedback on development and humanitarian policy and practice. They do not necessarily reflect Oxfam policy positions. The views expressed are those of the author and not necessarily those of Oxfam.

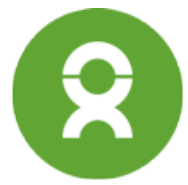




\section{CONTENTS}

Acronyms 3

Executive Summary $\quad 4$

1 Introduction 9

Research Questions 9

Conceptual Framework $\quad 10$

Significance of This Study $\quad 10$

2 Context 12

The Crisis in Education $\quad 12$

LFPS and PPPs in Pakistan 13

The World Bank's Approach to Private Schools and PPPs in Pakistan 16

Punjab Education Foundation (PEF) and Its Programs 19

3 Methodology 23

Research Design and Sampling $\quad 23$

Limitations of the Study $\quad 25$

4 Findings 26

Equitable Access for Marginalized Populations 26

Quality of Education $\quad 33$

Democratic and Social Accountability $\quad 43$

Wider Systemic Issues $\quad 46$

5 Discussion of Key Findings $\quad 51$

Equity $\quad 51$

Quality $\quad 52$

Accountability $\quad 52$

6 Conclusion $\quad 54$

$\begin{array}{ll}\text { Bibliography } & 55\end{array}$

$\begin{array}{ll}\text { Endnotes } & 62\end{array}$

$\begin{array}{ll}\text { Acknowledgements } & 64\end{array}$ 


\section{ACRONYMS}

\begin{tabular}{|c|c|}
\hline ADB & Asian Development Bank \\
\hline ASER & Annual Status of Education Report \\
\hline CPD & Continuing professional development \\
\hline CPDP & Continuing Professional Development Program \\
\hline CSOs & Civil society organizations \\
\hline DFID & UK Department for International Development \\
\hline EFA & Education for All \\
\hline ESPS & Education Sector Plans \\
\hline EVS & Education Voucher Scheme \\
\hline FAS & Foundation Assisted Schools \\
\hline IBRD & International Bank for Reconstruction and Development \\
\hline IDA & International Development Association \\
\hline IFC & International Finance Corporation \\
\hline KP & Khyber Pakhtunkhwa \\
\hline LEAPS & Learning and Educational Attainment in Punjab Schools \\
\hline LFPS & Low-fee private schools \\
\hline NEP & National Education Policy \\
\hline NGOs & Non-governmental organizations \\
\hline NSP & New School Program \\
\hline PEF & Punjab Education Foundation \\
\hline PESP I, PESP II, PESP III & First, Second and Third Punjab Education Sector Projects \\
\hline PESRP I, PESRP II & First and Second Punjab Education Sector Reform Programs \\
\hline PIEP & Punjab Inclusive Education Project \\
\hline PPP & Public-private partnership \\
\hline PSSP & Public School Support Program \\
\hline QAT & Quality Assurance Test \\
\hline SABER & Systems Approach for Better Education Results \\
\hline SDGs & Sustainable Development Goals \\
\hline SESP & Sindh Education Sector Program \\
\hline TEACh & Teaching Effectively All Children \\
\hline WDR & World Development Report \\
\hline
\end{tabular}




\section{EXECUTIVE SUMMARY}

Public-private partnerships (PPPs) in education are increasing in profile as countries grapple with serious challenges of educational access and quality-and as donors such as the World Bank turn to this approach as they advise countries on potential solutions to these barriers. Evidence is still limited on the impacts of this policy approach, however, and the academic literature that looks at equity and inclusion raises profound concerns.

With the second largest population in the world of out-of-school children; fewer girls than boys in school; limited access to schooling for children with disabilities and the poorest communities; and serious education quality and learning deficits, Pakistan faces steep challenges in fulfilling the right to education, which has been enshrined in Article 25A of the constitution since 2010. Public spending on education in Pakistan has hovered at just above 2 percent of GDP in recent years; ${ }^{1}$ one of the lowest levels in the developing world and well below international benchmarks. Low-fee private schools have mushroomed across the country, filling gaps in access where public schools do not exist or lack decent quality; however, they tend to locate in wealthier villages and settlements, and face their own serious quality constraints.

In this context, PPPs that subsidize low-fee private schools are being pursued by the governments of Punjab and Sindh provinces with donor support, as a means of expanding educational access and improving the quality of schooling. This study examines the PPP in Punjab province administered by the semi-autonomous Punjab Education Foundation (PEF). The PPP has been funded in part by the World Bank through a series of loans to the provincial government totalling $\$ 1.7$ billion over nearly 10 years, ${ }^{2}$ though a substantial portion of this support has gone to improving the public education system. ${ }^{3}$

PEF's four programs employ various PPP models, including a voucher program (providing tuitionreplacement vouchers for students to be spent in low-fee private schools); a program that provides per-student stipends to existing low-fee private schools; another that funds the establishment of new schools in rural or underserved areas; and a public school takeover program which transfers the management of public schools to private entrepreneurs and civil society organizations. PEF requires schools to meet a minimum pass rate on a standardized test in order to receive funding. The World Bank has promoted the initiative as a success to be replicated by other countries, citing evaluations that find improved test scores and expanded enrollment.

This study seeks to understand the impact of the Punjab PPP initiative on key dimensions of equity, education quality, and democratic and social accountability. It was conducted over a period of two months, through field visits in a sample of 31 schools across five districts of Punjab province (in both rural and urban/slum areas) and all four PEF programs. It employs in-depth semi-structured interviews with school principals and owners in the sample, supplemented by focus group discussions with teachers, field observations of sampled schools, and interviews with key stakeholders. Qualitative by design, the study seeks to go beyond macro-level enrollment and test score data to provide a picture of the school-level dynamics of the PPP program, and to contextualize and interpret the existing data.

While the sample size limits definitive statements about impact across all the PPP schools in the province, the study's findings are indicative of potentially far broader trends. The study provides an indepth view of how the sample schools are operating and are incentivized within the framework of the PEF program, raising serious concerns about equity, quality, and accountability that need to be considered more broadly in the PPP program. 


\section{Equity}

School principals and owners reported that:

Very few children in the PPP schools were previously out-ofschool. Of the student population of 12,502 in the sample, the reported number of previously out-of-school children was 158, a mere 1.3 percent. Interviewees overwhelmingly highlighted that PEF schools are not catering to the large out-of-school populations in their communities, whether in rural areas or urban/slum areas. This is particularly relevant given that a major objective of the program is to reach out-of-school children.

\begin{abstract}
"The poor go to the government schools in the area. They cannot afford any expenditure on education... We as school owners cannot ensure the education of everyone and include the poorest of the poor in this school with other kids. It's not like a charity, we have limited funds from PEF..." (Interview with principal, School No. 1)
\end{abstract}

Very few children with disabilities were accessing the schools in the sample. Only 11 students out of 12,502 were reported to have a disability, and none of those children were funded by PEF. Most schools were not physically accessible and none had a special needs teacher. Despite a recent provincial government focus on inclusion and a project to reach children with special needs in a small sub-set of PEF schools, findings showed no reasonable accommodation for such students in the schools in this study.

\section{Schools were actively screening and selecting children for academic ability, and the program's test-based funding model creates incentives for exclusion. Ninety percent of principals and owners in the sample reported that they administer screening tests when children apply for admission, and 60 percent admitted to refusing to admit children who had done poorly on the test. These practices appear to be resulting in the cherry-picking of more}

"Before admission we give a test. If the child performs poorly we don't admit them into the school. We do not want weak children because we have to pass the QAT..." (Interview with principal, School No. 22) desirable students and avoidance of students who-because of disability or lack of previous schooling or investment due to income or gender-may be less likely to perform well on PEF's Quality Assurance Test (QAT), which determines school funding.

In the voucher program, school owners reported that they selected students to receive the voucher, not the other way around, and that they charged students a fee for the first year before admitting them to the PEF voucher program. This suggests that students who cannot afford fees are not able to access vouchers, and raises questions about whether the concept of "school choice" is a reality in the program.

Gender parity is not being achieved in most of the schools sampled. Among co-ed schools (about two-thirds of the sample), 75 percent had more boys than girls; when including girls' schools, of the total sample 65 percent had more boys. High dropout rates, particularly among girls, were also reported. Findings suggest that schools in the program are unlikely to be contributing to improving gender parity rates, particularly given a lack of PEF policies or funding to target girls.

Non-fee expenditures are a significant financial barrier to access for the poorest children. Although school fees are covered by the program, the study finds that on average, parents spend between PKR 14,750 (\$127) and PKR 17,300 (\$150) each year (see Table 1 below) on other expenses such as uniforms, meals, books, and transportation. These costs for one child could represent half of the income of a parent living at the poverty line, suggesting that the poorest families cannot afford the expenditures associated with these schools. 
Table 1: Non-fee expenditures in PEF schools

\begin{tabular}{|c|c|}
\hline Items of expenditure & Cost in PKR per year (PKR $1=\$ 0.0086)$ \\
\hline School uniform & $750-1,200$ \\
\hline Shoes & 900 \\
\hline Stationery (notebooks, pencils, etc.) & 2,000 \\
\hline Transport & $\begin{array}{l}6,400-8,000 \text { (depending on distance, } 800-1,000 \text { per } \\
\text { month) }{ }^{4}\end{array}$ \\
\hline Lunch & 4,000 \\
\hline Private tuition & $200-700$ \\
\hline School bag & 500 \\
\hline Total per student & $14,750-17,300(\$ 127-150)$ \\
\hline
\end{tabular}

\section{Education quality}

The findings also raise questions about the quality of education and teaching being provided in the low-fee private schools in the program. The study looks at a number of factors that affect education quality, in order to build a more complete picture of the quality of learning that is happening in PPP schools and to contextualize the testing data.

PPP schools are utilizing an under-qualified teacher workforce, with very limited access to training or support. Of the 497 teachers in the sampled schools, 57 percent had a grade 12 qualification or lower. About half of the schools reported that they had not received any teacher training from PEF in the past five years, and the remainder reported very infrequent training opportunities. Principals and teachers expressed concerns that the training they did receive was not relevant in helping them serve the needs of children from marginalized backgrounds in multi-grade classrooms with limited resources.

Strong concerns were raised about the quality of instruction, curriculum and the practice of teaching to the test. School principals and teachers alike cited concerns about the appropriateness of the curriculum and textbooks being used, the weakness of the QAT as an assessment tool, and reported a reliance on rote memorization and teaching to the test as a result of the high-stakes testing environment.

Schools rely predominantly on a female workforce, where average reported teacher salaries were less than half the "...the syllabus we have to follow is all based on rote memorization. We are teaching to the test. You teach your kids the QAT format and practice on past paper guides being sold in the market. There is no conceptual learning taking place in the schools. I don't think quality is a goal of PEF..." (Interview with principal, School No. 3) minimum wage; suggesting that the system relies on gender inequity in the labor market. From the ranges provided by school owners, the average monthly salary of a PEF schoolteacher in the sample was calculated at PKR 6,000 (\$52); magnitudes lower than that of a public school teacher. Meanwhile, 88 percent of teachers in the sampled schools were female. The findings suggest that female teachers are being paid very low wages on account of their gender, their limited mobility, and their low rates of participation in the labor market. They suggest that this is a violation of their right to decent work, and that the low-fee private school PPP model relies on this reality to achieve low perstudent costs. School owners and principals also indicated the program funding levels prevented them from investing more in "You cannot give quality on PKR 550 [\$4.73] per child. You cannot give quality with teachers who have only done Grade 10 or 12 themselves and have zero training opportunities. No owner can invest in training, and nobody does." (Interview with principal, School No. 25) teachers and their training, and led to high turnover rates for teachers. 


\section{Number of schools, from total sample of 31}

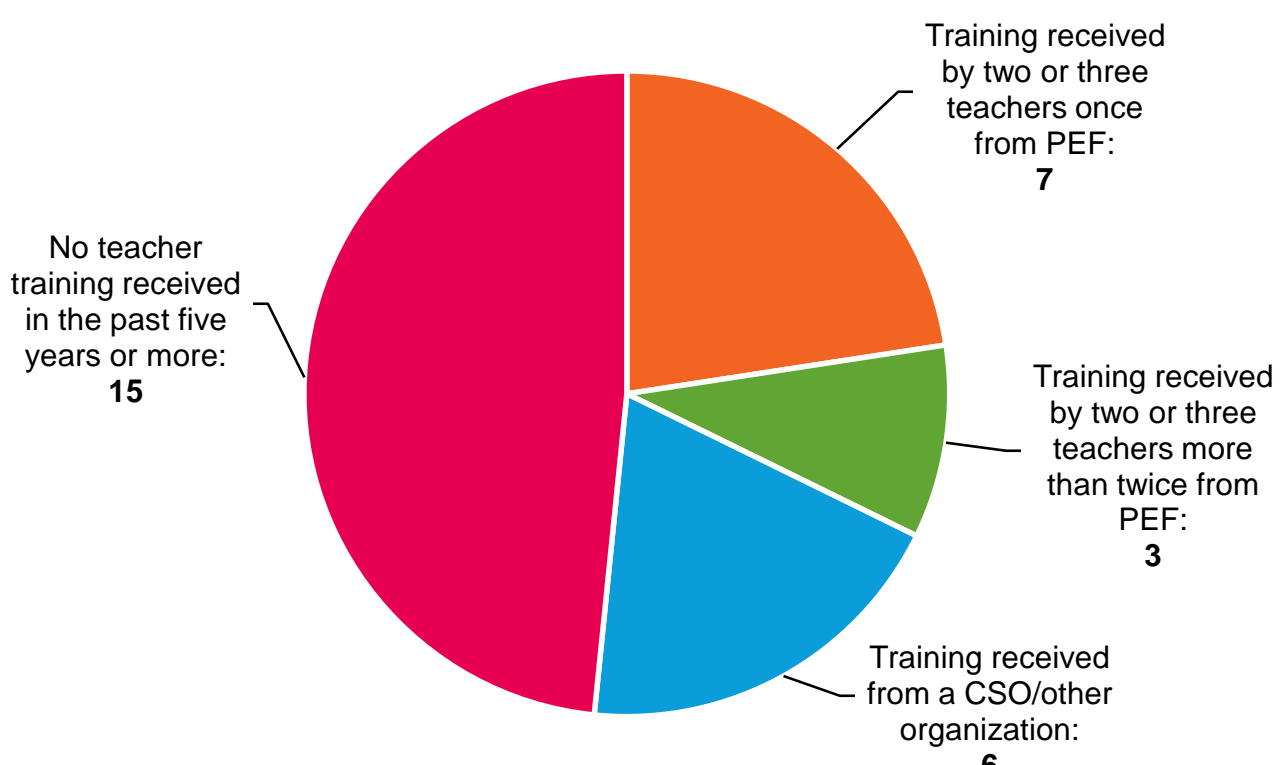

6

A high prevalence of after-school private tuition (tutoring) was reported, raising questions about whether test scores are an accurate measure of school performance without taking this factor into account. Lower-income students and girls are also likely to be disproportionately excluded due to cost barriers associated with private tuition.

Most schools did not have adequate physical infrastructure or materials needed to create a good learning environment. Of school owners in the sample, 85 percent argued they did not have sufficient funds to meet their basic infrastructure needs. While most schools did have separate washrooms for girls and boys, the majority lacked an adequate number of classrooms, desks and benches; adequate lighting; outdoor space for children to play; and other facilities such as libraries.

\section{Democratic and social accountability}

None of the schools in the sample had a school management committee or parent-teacher council. While the lack of parent perspectives in this study is a limitation, feedback from owners and teachers provides important insight into the lack of structures available for parent and community engagement and oversight in PPP schools. School choice is often assumed to lead to greater accountability in schools; however, respondents raised questions about whether parents were able to exercise any meaningful choice in selecting schooling for their children.

\begin{abstract}
"There is no choice for students and their parents in this context. Sometimes it's the only school they can send their child to. There is no competition for [voucher school] owners; they know that parents will send their kids here, so why work extra? There is no competition in terms of quality and learning. PEF school owners are only concerned about the QAT..." (Principal, School No. 7)
\end{abstract}

Schools reported that monitoring and inspection of schools was biased, potentially subject to bribes, compromised the accuracy of school data, and did not create a sense of partnership. Many school principals, owners, and teachers reported that PEF monitors were treating school staff and children disrespectfully, leveling unfair fines, and accepting payments, for example in exchange for reporting higher enrollments or a good school report. While accusations of misconduct could not be verified, the findings suggest that PEF's punitive method of oversight is creating distrust among private providers and may result in ineffective oversight. These findings also call into question the accuracy of the data provided by PEF about its schools and programs. 
Beyond the findings related to equity, quality, and accountability, interviews with various stakeholders brought out their views about the broader context of the initiative, including concerns around the sustainability of the PEF program and lack of planning for its place in the education system; the influence of donors on education policies; and the fear that investment in the PPP program was undermining investments in improving the quality of the public school system.

\section{CONCLUSIONS}

The study raises questions about the validity of a number of key claims made about PPPs-that they are more cost-effective than other options and that they provide better quality education while sidestepping inefficiency in the public sector. The interviews demonstrate that in the schools in the sample, cost savings come at a high price, and that schools are sacrificing quality due to a lack of investment in qualified teachers, relevant training and support, and adequate facilities. Furthermore, bias and irregularities in the monitoring and inspection of schools suggest that bribery practices and inefficiency are systemic challenges not limited to the public sector.

The study also sheds light on the unintended consequences of a high-stakes 'reward and sanction' incentive model in which schools' funding is tied to student performance on a standardized test. The findings suggest that this approach creates disincentives for schools to cater to the poorest and most marginalized children and children with disabilities. It raises concerns that this PPP approach may not be effective in addressing the real challenges in delivering quality education in Pakistan, and may instead risk deepening economic and gender inequality by creating greater disparities in educational access and outcomes.

Attention must be refocused on improving the quality of public education, which requires sustained and committed government leadership, and donor support. The World Bank, other donors, and leaders and policy-makers in Pakistan must reflect on the lessons of this study and investigate the concerns being raised in order to effectively fulfill their obligation to provide access to quality education for all children, regardless of whether they live in poverty, or experience discrimination based on their gender or disability. 


\section{INTRODUCTION}

The debate on the scope and impact of the private sector in the provision of education to achieve Education for All (EFA) ${ }^{5}$ and the Sustainable Development Goals (SDGs) has attracted greater attention in recent years. Struggling and underfunded public education systems, and the growth of private schools in response to demand for schooling in many developing countries, have led some stakeholders to advocate for programs that fund private sector schools. Many such efforts are advanced under the banner of public-private partnerships (PPPs) - though this term can sometimes be misleading, as such partnerships involve the private sector in a variety of different ways.

In South Asia, Pakistan is often cited as an example of a country at the forefront of this trend and a case where the government-especially in Punjab province-has actively been directing public resources to low-fee private schools (LFPS) for the provision of education. In 2015, The Economist published an article entitled Learning unleashed, which declared Punjab to be the "new standard bearer for market-based education reform," ${ }^{6}$ putting the province in the global spotlight. Around that time, the Government of Punjab announced a policy that halted the establishment of new public, government-run schools and instead focused on school expansion by means of a PPP via the semiautonomous Punjab Education Foundation (PEF). This was a bold move, especially since little independent research has been done on the impact of PEF's programs and the LFPS model they promote. A more recent piece in The Economist in January 2018 noted the frenzied pace of education reform in Punjab yet, despite the limited evidence, still held it up as a successful case study from which other countries could learn. ${ }^{7}$

At present Punjab's population of out-of-school children (aged 6-15 years) is over 5.5 million, and approximately 16 percent of children aged 6-15 have never attended school (World Bank, 2016). A key question that needs to be answered is whether PEF's programs are successfully targeting this population of marginalized children, especially girls and students with disabilities. It is also essential to ask whether the quality of education and teaching in PEF schools is helping to prioritize learning. The World Bank's World Development Report (WDR) 2018 clearly states: "Schooling without learning is a wasted opportunity." ${ }^{8}$ Can the educational equity and learning crises of countries including Pakistan be solved by PPP reforms such as the one underway in Punjab? Given the dearth of existing studies in this area, the goal of this report is to advance understanding of the PPP scheme in Punjab, including its impacts on equity, key aspects of education quality, and the public education system.

\section{RESEARCH QUESTIONS}

This study poses questions in three main areas. First, it seeks to understand the impact of the Punjab PPP initiative (PEF-funded schools and programs) on equity in the affected communities. In particular, it asks whether marginalized populations are accessing schooling equitably under this model, with a particular focus on girls, out-of-school children, and children with disabilities; and whether school fees, other financial barriers, or non-cost barriers are impacting the access of marginalized groups.

Second, the study seeks to understand the quality of education being provided in PPP schools. It seeks to assess key holistic dimensions of quality in PPP schools, considering areas such as teacher qualifications, pay and training; quality of curriculum, materials and instruction; and school facilities, etc. It seeks to understand the role of the Quality Assurance Test (QAT) and the test-based funding model in shaping teaching and learning in PPP schools, as well as other factors such as the prevalence of private tuition (tutoring) and the presence of community participation and oversight mechanisms.

Finally, the study seeks to understand how key stakeholders view the sustainability of PPP programs in the long term and the effect of funding private schools on the public education system. 


\section{Human rights, equity, and quality}

This study relies on the concept of education as a human right, which provides a framework to better understand the effects of a PPP model utilizing LFPS on educational equity and quality. All children have a right to free basic education, enshrined in the UN's Universal Declaration of Human Rights in 1948, and the UN Convention on the Rights of the Child (1989). This right was reaffirmed at the Jomtien (1990) and Dakar (2000) global education conferences, by the UNICEF School Fee Abolition Initiative, the UN Secretary-General's commitment to "Education First" (2013), and in the more recent Education 2030 Incheon Declaration (2015). The Incheon Declaration reaffirms that "education is a public good, a fundamental human right and a basis for guaranteeing the realization of other rights" (UNESCO, 2015, p.7). This framework focuses on access, equity and inclusion, gender equality, quality, and learning. SDG 4, "Ensure inclusive and equitable quality education and promote lifelong learning opportunities for all," fully captures this in its corresponding targets (2015).

The right to education is also enshrined in Article 25A of Pakistan's constitution, which reads: "The State shall provide free and compulsory education to all children of the age of five to sixteen years in such manner as may be determined by law." The government of Pakistan has also ratified the UN Convention on the Rights of the Child.

As these international declarations show, equity and quality are fundamental in a rights-based approach to education and lie at the core of EFA and the SDGs. UNESCO stressed in a recent publication: "Inclusion and equity are overarching principles that should guide all educational policies, plans and practices, rather than being the focus of a separate policy" (UNESCO, 2017, p.18). The present study, though limited in its size and scope, looks at equity by focusing on how LFPS are funded and whether or not they ensure that all children from the poorest households, particularly outof-school children, girls, and students with disabilities, in the selected districts have access to and can complete free and compulsory education of good quality. It also looks at holistic indicators of quality that include teacher qualifications and training levels, the quality of materials/curricula, school facilities, accessibility, teachers' wages and working conditions, private tuition, and parental participation in demanding a quality education.

\section{SIGNIFICANCE OF THIS STUDY}

Together, the PPPs in Pakistan's Punjab and Sindh provinces constitute one of the largest and fastest-growing public-private partnerships in the world. These projects receive substantial government funding, and they form part of a broader package of World Bank loans to Pakistan for education over the past 10 years totalling $\$ 1.7$ billion (see Table 1 ) as well as funding from other donors. Given that a significant amount of resources is being directed to low-fee private schools instead of to a struggling public system, the effects of the PPP approach on educational access, equity, and quality need to be explored and analyzed.

This study takes an in-depth look at the various programs run by PEF and investigates some of the effects and outcomes of these programs in a sample of schools across five districts of Punjab. To do this, it employs qualitative methods to explore issues around process, partnerships, teaching, access, parental participation, costs, and other factors that are often missed in quantitative studies and in evaluations commissioned by the World Bank and other donors that take a predominantly economistic approach. The study considers in particular the role of the World Bank in financing this program, because of the institution's global reach in financing education and its influence on country policy choices; implications can therefore be considered for Bank programs and policy advice in other countries. 
From the rich insights and testimonies provided by various stakeholders interviewed for this study, certain patterns emerge around LFPS that have relevance for other urban slum and rural communities in Pakistan and in other developing country contexts. This study is both crucial and timely as World Bank support for education in Punjab enters its third phase, other donors continue their funding, and as PEF continues to expand its programs at a rapid pace, raising questions about the vision, impact, and sustainability of the PPP in Punjab province. 


\section{CONTEXT}

\section{THE CRISIS IN EDUCATION}

With one of the largest youth populations in the world, Pakistan is facing significant challenges in educating its population. The situation can justly be described as a crisis, as the country has the second largest population in the world of out-of-school children. The Pakistan Education Statistics 2014-15 factsheet compiled by non-governmental organization (NGO) Alif Ailaan (2016) shows that there were 24 million out-of-school children in Pakistan between the ages of five and 16 years, highlighting a huge challenge of access. The issue is compounded in the case of girls, as cultural beliefs and practices tend to discriminate against them, thus reducing the likelihood that they will attend a formal school (I-SAPS, 2016). Gender disparity is evident in school enrollment rates, with over half of all girls (52 percent) out of school compared with 43 percent of boys (Alif Ailaan, 2016, p.62). Enrollment rates fall dramatically after the primary level, but more steeply for girls than for boys. Boys continue to outnumber girls at every stage of education. At the primary level, nearly 10 million boys and 8.1 million girls are enrolled; this drops to 1.9 million boys and 1.4 million girls at the middle school level, and just 1 million boys and 700,000 girls at the higher secondary level (Alif Ailaan, 2016). The Annual Status of Education (ASER) report for 2016 shows that while gaps in enrollment have been narrowing over time, boys aged 5-16 are more likely to go to government and private schools compared with girls (p.12).

While data on children with disabilities in Pakistan is limited, the recent Teaching Effectively All Children (TEACh) research project has estimated that at least one in ten children experience difficulties that significantly impact an aspect of their daily functioning (Rose et al. 2018). A 2014 report states that there are approximately 50,000 children enrolled in special education schools in Pakistan, but that approximately 100,000 children with disabilities need education (British Council, 2014, p.33). Many special education schools, especially in Punjab, are located in cities and are inaccessible to the majority of students with disabilities who live in rural areas (Ibid., p.34). While private schools are sometimes favored as a source of better-quality education for children with disabilities, private schooling can be prohibitively expensive for many parents, and poor families may feel that their limited resources are better spent on educating their children without disabilities (Ibid., p.33). In addition, girls with disabilities face more discrimination by virtue of their gender and have very limited access to education and employment (British Council, 2014, p.6).

Pakistan's public expenditure on education, an important indicator of national development, has never reached the level required. It has remained at around 2 percent of gross domestic product (GDP) over the past few years; a recent estimate put it at 2.2 percent of GDP in 2017, compared with 2.3 percent in 2016 (Pakistan Economic Survey, 2018, p.157). This is far below the target of at least 4 to 6 percent of GDP recommended by the Education 2030 Framework for Action (UNESCO, 2015), and one of the lowest levels as a percentage of GDP in the developing world. The country's failure to provide basic public education and health services to its marginalized population is driven by its inability to introduce a fair and equitable system of taxation and to mobilize domestic resources for sustainable development (I-SAPS, 2016, p.4). 


\section{LFPS AND PPPS IN PAKISTAN}

\section{Defining PPPs and low-fee private schools}

Public-private partnership is a broad term that refers to an arrangement "between public and private actors for the delivery of goods, services and/or facilities," as described by Verger and Moschetti (2017, p.2). In the education sector, PPPs can take a number of forms, but for the purposes of this study, the focus is on partnerships with the private sector for the provision of education-in other words, the public funding of private schools, whether directly (via grants or per-student subsidies to schools) or indirectly (via vouchers for students/parents to use for the payment of school fees).

The term "low-fee private school" was originally coined by Prachi Srivastava (2006) to refer to unregulated, unregistered, and unrecognized private schools in India, but it has gained much currency and is widely used interchangeably with "low-cost private schools" to "loosely describe schools that charge minimal fees, cater to the poorer households in society, and are not managed by the government" (Sivasubramaniam, 2014, p.13). However, Srivastava (2013) also points out that it is difficult to analyze low-fee schools because they are so heterogeneous. The varying management, financing, ownership, and regulatory arrangements of such schools make it challenging to present a single definition that captures them in all their variety.

LFPS under a PPP arrangement are to some extent publicly-regulated and financed, and may or may not actually charge fees directly to students depending upon the model. This study therefore builds on Srivastava's and Sivasubramaniam's definitions, broadening them to include not just independent private schools which cater to poorer households, but also those which have some degree of public involvement, incorporating Kitaev's (1999, p.43) definition:

"Private education is ... all formal schools that are not public, and may be founded, owned, managed, and financed by actors other than the state, even in cases where the state provides most of the funding and has considerable control over these schools."

These definitions illustrate the complexity of distinguishing between private and public spheres in education, with different arrangements possible in relation to the provision of education, financing, and regulation (Rose, 2007).

\section{The rise in private schooling and PPPs in Pakistan}

The growth of private schooling in Pakistan is in part a response to an increasing demand for education from a rapidly expanding school-age population, as well as a reflection of the public sector's lack of capacity to attract and provide education for all of these potential students (ILM IDEAS, 2014). The number of private schools has multiplied at a much faster rate than the number of public sector schools. Between 1999-2000 and 2007-08, the number of private schools increased by 69 percent, as compared with a mere 8 percent increase in the number of government schools (I-SAPS, 2010). Most of this growth has been in LFPS, which now account for 30 percent of total enrollment (Government of Pakistan, 2014).

Private schools operate at different levels and offer services to all socio-economic segments and all areas of Pakistan. The sector is characterized by a wide range of fee structures and diverse operating models, ranging from single elite schools and large networks of schools catering to the upper- and middle-income segments of the population to LFPS that cater to lower-middle and low-income households (ILM IDEAS, 2014). LFPS are privately owned and operated and charge low fees, typically ranging between PKR 10 (\$0.86) and PKR 2,500 (\$22) per month (Ibid.). For the past decade, the private education sector-especially at the primary level-has been one of the fastest-growing subsectors of the education industry in Pakistan. With an estimated 70,000 LFPS currently operating in 
the country, this is a sector that is providing schooling to a significant percentage of the population (Ibid.).

LFPS are particularly prevalent in the wealthier and more populous Punjab province. The Government of Punjab, with support from donors such as the World Bank, has piloted and adopted the inclusion of LFPS in PPP frameworks and in 2016 it announced that no new public schools would be built in the province; instead public funding would support establishing or subsidizing LFPS. The province has been promoting these schools through PPP modalities that are managed and financed through the PEF. This quasi-governmental organization channels public financing to private sector schools through a number of initiatives, ranging from vouchers to its Foundation Assisted Schools (FAS) program.

Influenced by international and donor discourse, the Government of Pakistan has adopted PPPs as a primary strategy to address issues of access, quality, and equity in education. A 2003 government document states: "The Education Sector Reform is anchored in development of partnerships between the private sector, civil society organizations, and the public sector. Public-private partnerships are critical to reaching the goals of access and quality at all levels of education creating possibilities for both voice and choice and improved service delivery" (Government of Pakistan, 2003, p.70). The influence of international development institutions such as the World Bank, USAID, and the Asian Development Bank (ADB) in promoting the idea of PPPs is evident in both government and donor documents, and many of these strategy documents pre-2015 frame PPPs within Millennium Development Goal (MDG) 8, "Develop a global partnership for development" (Government of Pakistan, 2003).

Aslam et.al (2017, p.84) note that:

"2010 was a landmark year for education and PPPs in Pakistan, with education elevated as a fundamental constitutional right under Article 25A for all children aged 5-16 and the provinces of Punjab and Sindh passing provincial PPP Acts, which were largely focused on infrastructure. Subsequently, both provinces have issued new acts and amendments-the Punjab Public Private Partnership Act 2014 and the Sindh PPP (Amendment) Act 2015—which include services beyond infrastructure across all sectors and provide a framework for public financing of services through transparently procured partnerships."

PPPs in education are covered under the National Education Policy (NEP) 2009 and more recently the Education Sector Plans (ESPs) for both Sindh and Punjab (Ibid., p.86).

While these initiatives appear to have supported the provision of education at lower cost, they also give rise to concerns about equity (Malik and Rose, 2015). Across the country, there are great discrepancies in who is able to access private schooling. Of those surveyed by ASER, only around 10 percent of children in school from the poorest households in rural areas are in private schools, compared with 40 percent of those from the richest households (ASER, 2016). In addition, there is a clear gender divide among the poorest children; after controlling for other factors, in rural Pakistan the poorest girls are 31 percent less likely to attend private schools than are the poorest boys (Alcott and Rose, 2015). Across the whole education sector, the ASER survey further strengthens the evidence base that socio-economic factors are adversely affecting the learning levels of children in Pakistan, as learning levels are directly related to wealth status. The ASER report concludes that structural disparities linked to wealth, gender, ethnicity, language, disabilities, and other markers of disadvantage are jeopardizing the education of millions of children in Pakistan and fueling wider processes of social exclusion (ASER, 2016).

In addition to equity, there are concerns about the quality of education in LFPS. Although private schools may sometimes be of better quality than government schools, the literature suggests that many children are not learning regardless of the type of school they attend, which suggests that problems of quality are endemic in the education system (Malik and Rose, 2015, p.8). For example, among 10-12-year-olds in rural government schools, one-third cannot read sentences, while in rural private schools more than one-fifth are unable to achieve this task, a standard they are expected to 
have reached by Grade 2 (Ibid., p.8). Furthermore, studies conducted in LFPS show that teachers in such schools have no training and are under-qualified (Afridi, 2017; Alif Ailaan, 2014). A major World Bank-funded longitudinal study, Learning and Educational Attainment in Punjab Schools (LEAPS), reported that private schools outperformed public schools for comparable student populations (Andrabi et al., 2008). However, as a reviewer of the LEAPS report put it: "The only reason the private schools look so good is that the poorly performing public schools are so disastrous: if at some future date, children actually started demanding something more than the most rudimentary education, the semi-educated teachers in the private schools would actually find it hard to cope" (Ibid). This is a concern also noted by others (Khan, 2004).

While there is recognition that the private sector has helped to absorb demand for schooling, there is considerable skepticism among researchers about the sustainability of these initiatives in Pakistan (Malik and Rose, 2015). While some (Malik, 2010; Riboud, 2005) have seen PPPs as producing positive outcomes, especially in Punjab, others (such as Bano, 2008) reflect on the limited potential of PPPs to become the primary vehicle to address fundamental challenges to the provision of education for all. Bano (2008) notes that private schools are severely limited in their ability to provide access to education for the large number of children from lower-income groups and that they do not address the issue of equity. Moreover, the LEAPS study shows that access to private schools is not universal; rather, private schools choose to locate in richer villages and richer settlements within villages, limiting access for poor households (Andrabi et al., 2008). This finding matches the national trend: private schools are expanding more rapidly in the more prosperous provinces of Punjab and Khyber Pakhtunkhwa (KP) than in rural Sindh or Balochistan. Between 1999 and 2001, the proportion of private schools increased from 15 percent to 30 percent of the total in Punjab and from 4 percent to 17 percent in KP, but grew only from 16 percent to 21 percent in Sindh and from 4 percent to 6 percent in Balochistan (Andrabi et al., 2008).

\section{Existing literature on access, equity, and quality of education in PPPs and LFPS}

Despite the promotion of PPPs in education by various stakeholders, the existing international research on their effectiveness in improving education systems is on the whole, limited and inconclusive. In their discussion of the literature on PPPs in education, Verger and Moschetti (2017, p.7) explain that while the proponents of educational PPPs describe their benefits in terms of expanding access, improving quality and equity, or promoting educational innovation, "the academic evidence to date suggests that results across these and other dimensions are not so clear-i.e. in learning outcomes, educational inequalities, efficiency, parental satisfaction, innovation, and teachers' working conditions."

Verger and Moschetti (2017, p.7) report that "while some studies have found positive effects of these interventions on learning outcomes (Di Gropello, 2006; Hoxby, 2003; Patrinos et al., 2009; Witte et al., 2007; Wolf et al., 2013), others argue that the impact is marginal or non-existent (Bettinger, 2005; Bifulco and Ladd, 2006; Cullen et al., 2005; Gauri, 1998)." In their rigorous review of the evidence on PPPs in education, including studies done on Pakistani PPPs, Aslam, Rawal, and Saeed (2017, p.8) find that "the body of evidence for the relationship between voucher provision and learning outcomes is mixed and inconclusive, and therefore insufficient." They find similarly that there is an insufficient body of evidence on contract/charter schools, but on subsidies for private schools they find a modest body of evidence for a weakly positive relationship to learning outcomes. The authors emphasize that "while there may be some evidence on the relative effectiveness of non-state schools (whether in a PPP or not) on improving learning outcomes, this comparison tends to be based on worryingly low levels of overall achievement across the entire education system and, therefore, any relative advantage associated with the non-state sector may still not be sufficiently large to alleviate quality concerns" (Aslam et al., 2017, p.8).

In the case of Pakistan therefore, an over-emphasis on private provision of education via PPPs is unlikely to improve the problem of access to very low-quality schooling among poor people (Bano, 
2008). Amjad and McLeod (2012) find that, while PPP schools display superior learning outcomes compared with government schools, private tuition (tutoring) is a key factor in the differences in performance. Without supplementary private tuition, PPP schools in Pakistan do not seem to do any better than government schools (Amjad and McLeod, 2012).

With regards to dimensions such as educational equity in PPP schools, Verger and Moschetti (2017, p.8) find that the evidence is not so balanced, as "most studies suggest that educational PPPs involving demand-side funding schemes tend to increase educational inequalities and socio-economic segregation in schools (Alegre and Ferrer, 2010; Valenzuela et al., 2014; Alves et al., 2015; Byun et al., 2012; Elacqua, 2012; Saporito, 2003; Sikkink and Emerson, 2008)." Existing research also points to the observation "that the competitive environments that many PPP frameworks have generated provide incentives for schools to recruit the best and 'cheapest to educate' students, as well as to discriminate against those who are less academically skilled or have special educational needs (Gewirtz et al., 1995; Jabbar, 2016; Jennings, 2010; van Zanten, 2009; Hsieh and Urquiola, 2003)" (Verger and Moschetti, 2017, p.8).

In addition, existing research raises the concern that the projected efficiency gains of PPPs usually come at a cost of worsening working conditions for teachers (Verger and Moschetti, 2017; Afridi, 2017; Termes et al., 2015; Lewin, 2013). Verger and Moschetti (2017, p.8) state that this "has implications for the quality of teaching and learning given that, in education, service quality is mainly determined by investment in human capital (Iossa and Martimort, 2015; Rosenau, 1999)." Researchers caution that the privatization of school provision, whether it happens under a PPP framework or not, "introduces important challenges to equity and quality goals in education" (Verger and Moschetti, 2017, p.9).

Lewin (2013, p.15), in his discussion of the privatization of education systems, argues that while "voucher schemes appear to offer opportunities to use public finance to support private service delivery with gains in competition, accountability, and efficiency, they change the nature of the relationship between the service provider and those receiving the services and involve significant transaction costs, with high expectations of capacities to administer and regulate." Highlighting the risks of vouchers, Lewin (2013, p.15) argues that "schools have incentives to minimize costs, especially teachers' salaries, once vouchers have been received and they may strategize to 'game' whatever performance indicators are identified." He further points out that "for families, school choice depends on information that may not be freely available and may be manipulated as providers within an area may collude to distort markets and bribe households to enroll children in exchange for a proportion of the value of the voucher" (Ibid, p.15). Lewin adds that "if top-up fees are allowed, schools may be stratified by price and this may result in the exclusion of poor children from the highestperforming schools" (Ibid., p.15).

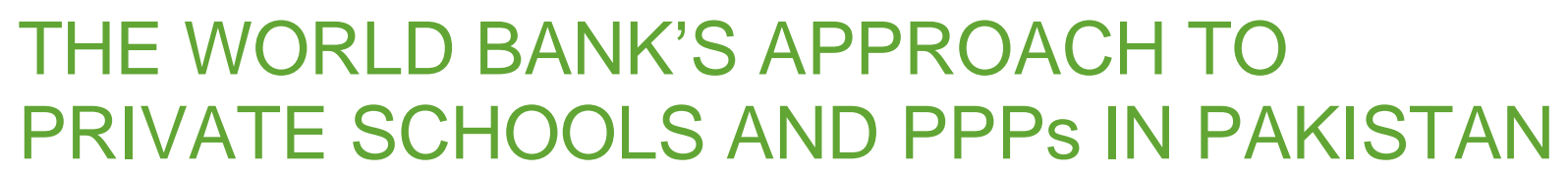

The World Bank is one of the largest external funders of education in developing countries, through the International Development Association (IDA) and the International Bank for Reconstruction and Development (IBRD), its public sector financing arms for low and middle-income countries. ${ }^{9} \mathrm{~A}$ substantial part of this funding supports governments to strengthen and expand the provision of public education; this is also true of the Bank's support for education in Pakistan.

At the same time, globally the World Bank has also been a key advocate for PPPs in education, through its policy advice, financing of country programs, and publications. In terms of financing, Mundy and Menashy (2014) find that during a five-year period from 2008 to 2012, the World Bank funded programs that included direct support for the private provision of education in seven countries spanning 10 projects (several in Pakistan) - this is 19 percent of the project documents reviewed in the study, a modest proportion of World Bank projects during this period, though not insignificant. 
Verger and Moschetti (2016) note that the first published reference to "PPPs for education" is found in the 2000 World Bank and ADB joint report The New Social Policy Agenda in Asia (Marshall and Bauer, 2000). Throughout the 2000s, several other publications, policy briefs, and toolkits were produced on PPPs by the Bank and its private sector finance arm, the International Finance Corporation (IFC). Most influential among them, the 2009 World Bank report The Role and Impact of Public-Private Partnerships in Education (Patrinos et al.) is a foundational piece in this series of publications dealing with alternative forms of education provision. In these publications, PPPs in education are often portrayed as cost-effective policy solutions to the access and quality issues that many education systems currently face, resulting from superior mechanisms of accountability and competition, especially in low- and middle-income countries (LaRocque, 2008; Patrinos et al., 2009, Mundy and Menashy 2014). Mundy and Menashy also find that on balance, the World Bank's publications and knowledge products "actively promote private sector provision" of education, and note that they draw almost exclusively from the discipline of economics. This approach is also found in the World Bank's SABER (Systems Approach for Better Education Results) framework What Matters Most for Engaging the Private Sector in Education (World Bank 2014). This framework forms the basis for the Bank's current policy advice to countries in this area, and informs a rubric that encourages governments to support the expansion of private schooling through public funding, among other policies.

More recently, the 2018 World Development Report (WDR) Learning to Realize Education's Promise takes a much more cautious approach toward the potential of private education provision, concluding that "there is no consistent evidence that private schools deliver better learning outcomes than public schools, or the opposite" (World Bank 2018, p.176). It discusses both the potential benefits and many risks of the growth in private schooling, and references PPPs as a useful strategy to expand enrollments quickly but also notes that for governments, "overseeing private schools may be no easier than providing quality schooling" (Ibid., p.177).

In Pakistan, the World Bank has played an instrumental role in promoting the private sector in education since the early 1990s (Menashy et al., 2014). Its support for private sector engagement in education has grown stronger over the years, with an increasing emphasis on PPPs. This has been underpinned by Bank-led research, especially the LEAPS study, which found positive outcomes in low-fee private schools in Punjab. The IFC has also conducted a study to identify and respond to the financing needs of LFPS and the educational market in Pakistan. ${ }^{10}$

The World Bank has generally viewed the growth of private sector involvement in education as a positive development in the context of the country in general and Punjab in particular. Its Project Appraisal Document report for the Second Punjab Education Sector Project (PESP II) states:

"One of the more significant positive developments in education in the province has been the dramatic growth in the private school system as reflected by the number of institutions. In addition, responding to the broad demand for greater access and better quality, the system has evolved in character, increasingly reaching low-income and rural households. This has produced a sizeable and rapidly expanding low-cost private schooling system which serves as an alternative to the government school system for low-income and rural households (the main clientele for government schools)" (World Bank, 2012, p.2).

Table 1 details World Bank education projects in Pakistan since 1995 that include a component of support for private provision of education; this component is in some cases a small part of the overall project. Relatively more intensive support for a PPP approach can be seen over the last ten years in the projects in Punjab and Sindh provinces, starting with the first Punjab Education Sector Program (PESP) and Sindh Education Sector Program (SESP), both approved in 2009. 
Table 1: World Bank projects in Pakistan that include a component of support for private education in $\mathrm{K}-12$, 1995 to $2017^{11}$

\begin{tabular}{|l|l|l|}
\hline Project name & Year & Amount (\$ million) \\
\hline North West Frontier Primary Education Project & 1995 & 150 \\
\hline Northern Education Project & 1997 & 22.8 \\
\hline Balochistan Education Support Project & 2006 & 22 \\
\hline Sindh Education Sector Project & 2009 & 300 \\
\hline Punjab Education Sector Project & 2009 & 350 \\
\hline Second Punjab Education Sector Project & 2012 & 350 \\
\hline Second Sindh Education Sector Project & 2013 & 400 \\
\hline Third Punjab Education Sector Project & 2016 & 300 \\
\hline Total & & $\mathbf{\$ 1 . 8 9 5}$ billion* $^{*}$ \\
\hline
\end{tabular}

* of which $\$ 1.7$ billion has been over the last 10 years. Source: World Bank Education Projects Database. http://datatopics.worldbank.org/education/wQueries/qprojects

In Punjab, the World Bank has engaged with the private sector by providing funding via the provincial government to the semi-autonomous PEF, which administers the PPP programs. This is part of its broader program of support to the provincial government's Punjab Education Sector Reform Program (PESRP) through PESP and its successor programs, which are financed by a series of investment loans totalling $\$ 1$ billion since 2009. Support to LFPS via PEF is described in World Bank project documents, beginning in the first PESP program, as a key strategic intervention to expand access and improve the quality of education, especially in underserved areas (World Bank 2009).

It is important to note that in PESP and its successors, other components of the projects include substantial support for strengthening aspects of the public education system, including the public provision of education. For example, in the most recent program (PESP III) other strategic areas include a focus on quality teaching and learning for all, which includes "improving the quality of ECE [early childhood education] in schools; strengthening the human resources management of teachers; reinforcing the field based CPD [continuing professional development] of teachers; and creating an enabling context for assessment activities" focused on improving assessment data (World Bank 2016, p.9). The project also includes support for improving leadership, management and accountability in the education system, as well as institutional capacity building, monitoring and evaluation (Ibid). However, specific financing amounts by component are not provided in the PESP project documents so it is unclear how much of the program is supporting the PPP element.

The PPP programs supported by the World Bank under PESP have a number of components. Through PEF the project finances tuition replacement vouchers, along with other PPP programs that offer per-student stipends directly to schools; these programs are designed to enable children from disadvantaged families to enroll in LFPS, and they operate under a results-based model that finances schools based on student performance on a standardized test (see next section for details on PEF's PPP programs). PEF's voucher programme has received funding from the Bank since 2012 through the second and third PESPs. As Bank reports explain, under the Education Voucher Scheme (EVS), cash is transferred to private schools to provide education to children with weak educational prospects from marginalized and less affluent areas in urban slums and shanty towns (World Bank, 2012). More recently, through PESP III the Bank is also supporting a PEF program to outsource existing public schools to private operators including entrepreneurs and NGOs.

The evidence base for the World Bank's investments in private schooling in Punjab is drawn mainly from the LEAPS study and other primarily World Bank-led research and evaluations, while the highly contested and inconclusive nature of the claims of educational benefits of LFPS and PPPS from research elsewhere is largely overlooked. In addition to providing access, the Bank argues that private schools produce more learning, and deliver education services more effectively and efficiently than public schools, in particular when incentives are employed (Andrabi et al, 2008; World Bank, 2016). A World Bank evaluation of the FAS program supported by PEF found that the program's design of linking the per-student subsidy to student learning was successful at pushing the schools to 
perform better, as measured by student performance on a standardized test (World Bank, 2012c), though it did not study the factors that may have led to this outcome or whether equity of access was impacted. Bank documents also advance arguments about the importance of school choice and the role of voucher programs in catering to parents, who perceive that private schools deliver a betterquality education (World Bank, 2016). However, in contrast with this discourse, much of the existing literature on Pakistan and globally (discussed in the previous section) points to a number of serious issues related to LFPS and vouchers, and questions the claim that they provide broad access, equity, or quality, especially for poor people.

The growth of PPPs in Punjab and in Pakistan more generally seems set to continue. The Bank, along with other bilateral and multilateral donors, is continuing to fund private schools in Punjab through PEF as part of the Third PESP. PESP III documents cite "large and quick gains in both enrolment and achievement" generated by the PPP initiative and therefore declare that PPPs will be a key feature of PESP III. The Bank also argues that under PESP I and II more broadly, the provincial government made many systemic improvements and has seen encouraging results (World Bank, 2016, p.2). It cites progress in the allocation and quality of teachers, in enrollment numbers, and in accountability systems, though it also reports issues with out-of-school children, poor learning levels, stagnant enrollment rates, low knowledge and skill levels of teachers, and performance management systems that do not foster accountability (World Bank, 2016). The Bank is not specific about how the program will ensure that PEF-funded schools are providing equitable access to the poorest households, to girls, and to students with disabilities. It mentions continuous development for teachers but turns a blind eye to the extremely low salaries that are paid to teachers and their poor working conditions in LFPS funded by PEF. The Bank discusses merit-based recruitment but does not discuss how that has been translated into practice in PEF schools.

More broadly, the Bank argues that its support for Punjab, as the province with the largest population, can influence the overall direction of the country's development and its policy decisions can open the way for other provinces to adopt similar approaches (World Bank, 2016; Riboud, 2005). At the start of the first education sector program, it was envisioned that improvements in education outcomes in Punjab would have a countrywide impact and that success here could lead to similar reform efforts in Pakistan's other provinces (Ibid.). Interestingly, over the past few years the World Bank has evaluated the PPP program in Punjab, including the FAS program, as a success and on this basis is recommending similar reforms in other developing country contexts, for example through its SABER policy framework for engaging the private sector (World Bank 2014, p.21).

While the existing literature in Pakistan raises significant concerns regarding LFPS, there is still very little independent research on the PPP programs administered by PEF, or the World Bank support for these programs. This study, though it focuses on the PEF programs at the school level, also considers the World Bank's role because of the institution's broad influence in setting education policy agendas, both within Pakistan and globally. As a multilateral institution tasked with helping to implement the education SDG globally, the World Bank's role in promoting the PPP agenda must also be better understood.

\section{PUNJAB EDUCATION FOUNDATION (PEF) AND ITS PROGRAMS}

The PEF runs a number of education programs in Punjab through a PPP model. PEF came into being in 1991, and was restructured in 2004, as an organization that would facilitate and fund the private sector in the provision of education in the province. Asserting that PPPs are "an efficient and timetested mechanism to encourage and promote market-based social entrepreneurship" (Malik, 2007, p.41), PEF's mission is the "promotion of quality education through Public-Private-Partnership, encouraging and supporting the efforts of private sector through technical and financial assistance, innovating and developing new instruments to champion wider educational opportunities to the underprivileged children at affordable cost." 12 
PEF aims to provide "better quality education through the private sector to low income households."13 The program requires schools to meet a minimum pass rate on a standardized test, the QAT, in order to receive funding. According to its 2016 annual report, the key objective of its programs is to cater "to the needs of underprivileged, disadvantaged, out of school, and drop out" children in the province (PEF, 2016, p.24). The report also mentions that PEF, with the support of the Punjab education department, has successfully launched a pilot program of "inclusive education in its partner schools with the objective to educate children with minor disabilities in seven districts of Punjab" (Ibid., p.21). With regards to gender, PEF's website states that one of the features of its strategy is "preference for female education" and its annual report states that " $45 \%$ of its sponsored students in PEF schools are girls" (Ibid., p.4); however, it lacks a clear policy statement on gender parity in its schools.

Furthermore, PEF's stated objectives include providing incentives to teachers and assisting educational institutions with capacity-building, including the training of teachers (Ibid., p.8). However, the annual report does not contain information on the frequency of organized teacher training in a given year or the effectiveness of teacher training in PEF schools.

PEF receives most of its funding from the Government of Punjab, with support from donors such as the World Bank and the UK's Department for International Development (DFID) (World Bank, 2016, p.13). In addition, it has received support from the Asian Development Bank. While details of the World Bank's support for PPP projects in Pakistan are available through its project documents, we do not know the percentage of the overall loan or the exact amount that has been allocated to PEF for its projects; Bank staff were not able to provide this information to the researcher. ${ }^{14}$ Funding from the Bank to PEF is channeled through the Government of Punjab, which is the recipient of the loan. World Bank documents for PESP III indicate that its financing for the provincial government constitutes about 2 to 3 percent of the total forecasted yearly education expenditure. DFID has been a parallel financier of PESRP I and II (World Bank, 2016, p.5) and, as part of its continuing support to the program, has allocated £68.6 million to fund PEF's programs including the Education Voucher Scheme, New Schools Program and Foundation Assisted Schools program (DFID, 2017). It has also has directed £9 million to provide access to finance for potential entrepreneurs in the LFPS sector (DFID, 2017). In total, DFID has allocated $£ 420.5$ million over six years to support the provincial government's education program, making it the UK agency's largest bilateral program globally for education (DFID, 2017).

At present PEF works under the School Education Department of the Government of Punjab. Its funds are overseen by its own managing director. Government officials head the management of PEF, although its field and program officers can also be hired via a private application process. Government officials involved in PEF's Board of Directors have included administrative secretaries from the Punjab government; members of parliament; principal secretaries to the Minister of Education; special secretaries of higher education and schools; chairmen of the province's Boards of Intermediate and Secondary Education; and academics (PEF, 2016). Therefore, from both a financial perspective and in terms of management of its programs, PEF would appear to be a largely government-directed organization.

PEF's website reports that it currently funds over 8,700 schools, which cater for 2.4 million students, through its four programs: Foundation Assisted Schools (FAS), the Education Voucher Scheme (EVS), the New School Program (NSP), and the Public School Support Program (PSSP). ${ }^{15}$ The organization is currently working in all 36 districts of Punjab and has a sizeable budget, which has continued to increase since 2011 (see Table 2). 
Table 2: PEF's annual budget, 2011-18

\begin{tabular}{|l|l|l|l|l|l|}
\hline \multirow{2}{*}{$\begin{array}{l}\text { Financial } \\
\text { year }\end{array}$} & \multicolumn{2}{|l|}{ Allocation of funds } & \multicolumn{2}{l|}{ Total expenditures } & Remarks \\
\cline { 2 - 6 } & (in million PKR) & (in million \$) & (in million PKR) & (in million \$) & \\
\hline $2011-12$ & 6,000 & 52 & 4,848 & 42 & \\
\hline $2012-13$ & 6,500 & 56 & 6,223 & 54 & 72 \\
\hline $2013-14$ & 9,126 & 79 & 8,328 & 85 & \\
\hline $2014-15$ & 9,898 & 86 & 9,852 & 119 & 161 \\
\hline $2015-16$ & 12,531 & 108 & 13,747 & 133 & Unaudited \\
\hline $2016-17$ & 17,181 & 149 & 18,648 & 15,408 & Expenditure \\
till 31 \\
2017-18 PEF
\end{tabular}

Source: PEF website, accessed June 2018. http://pef.edu.pk.pefsis.edu.pk/About/about-pef-budget.aspx.

At present $P E F$ is running these four programs along with a Continuous Professional Development Program (CPDP). The CPDP provides opportunities for development for teachers in PEF schools by supporting and organizing regular in-service teacher training workshops to improve teachers' content knowledge and teaching skills. In more detail, the four core programs of PEF are as follows:

1. Foundation Assisted Schools (FAS): The FAS program provides funds to private schools in order to improve the quality of schools that serve financially deserving students from marginalized populations. Under this program, financial assistance is paid to partner schools per child on a monthly basis. Begun in 2005 in six districts, the program now funds schools in all 36 districts of Punjab, with around 3,200 partner schools and a student population of 1.6 million. ${ }^{17}$

2. Education Voucher Scheme (EVS): The EVS was launched in 2006 to target children from less affluent households in urban slum areas and rural areas by providing them with tuition-replacement vouchers. Under the scheme, private entrepreneurs and various organizations running schools, including civil society organizations (CSOs), are chosen on PEF's criteria and receive per-child funding by means of a voucher. Over a period of 10 years, EVS has launched 15 phases in all 36 districts of the province, and approximately 490,509 children are registered in more than 1,730 EVS partner schools. ${ }^{18}$ The age range of EVS beneficiaries is 5-16 years.

3. New School Program (NSP): The NSP was launched as a pilot project in 2008 to engage with private sector entrepreneurs to set up new schools in remote, distant, and under-served areas of the province, where government or private schools are unavailable or very few in number. Currently, NSP has 2,126 schools across the 36 districts of the province. ${ }^{19}$

4. Public School Support Program (PSSP): Under this program PEF, through a private operator, is responsible for running low-performing public schools handed over to it by the provincial government. The program's objectives are to increase enrollment, especially of out-of-school children, and improve the quality of education in low-performing public schools. A report by the Punjab Education Secretary provides a breakdown of individuals and entities who have taken over outsourced schools: 1,793 schools have gone to non-governmental or community organizations, 145 to retired government servants, 395 to private individuals, 196 to private school owners, 736 to private school chains such as Beaconhouse, and 1,010 to other organizations that PEF has worked with. ${ }^{20}$ Currently the private sector is operating 4,300 government schools, but the chief minister of Punjab has directed PEF officials to expand the program to 10,000 schools. ${ }^{21}$ 
Table 3: PEF's programs, by district and number of schools

\begin{tabular}{|l|l|l|}
\hline Name of program & Districts & Number of schools \\
\hline Foundation Assisted Schools & 36 & 3,500 \\
\hline Education Voucher Scheme & 36 & 1,665 \\
\hline New School Program & 36 & 2,126 \\
\hline Public School Support Program & 36 & $4,300^{22}$ \\
\hline
\end{tabular}

Source: PEF website, Accessed July 2018.

http://pef.edu.pk.pefsis.edu.pk/fas/index.aspx

http://pef.edu.pk.pefsis.edu.pk/evs/index.aspx

http://pef.edu.pk.pefsis.edu.pk/nsp/index.aspx 
This study employed qualitative methods of semi-structured interviews, focus group discussions, and field observations to answer the main research questions. In addition, it includes relevant literature (policy documents, government archives, program evaluations, school brochures and marketing materials, etc.) and sources (e.g. local research think-tank reports, community-level census data, ASER survey results, etc.) where needed.

Many of the previous studies conducted on LFPS and PPPs in education in Pakistan have employed quantitative data and econometric techniques (Andrabi et al., 2008; Andrabi et al., 2015; Amjad and McLeod, 2012; Barrera-Osorio et al., 2015; Malik et al., 2015), test scores (Malik, 2010), and largescale data. This study, by contrast, has employed qualitative techniques that go beyond enrollment numbers and test scores and looks at issues of access, equity, and quality in depth, including the views of various stakeholders. This approach was chosen because previous quantitative studies may not be providing a full picture of the situation in PEF-funded schools, especially when it comes to accountability and transparency in the selection and workings of LFPS. Equity, which is a major concern in the diversified Pakistani education system and a key part of ensuring Education for All, is largely missing from the quantitative studies, which merely state that poor households are benefitting, without elaborating on how they reached that conclusion. Therefore, in an effort to obtain an in-depth view of LFPS funded by PEF, this study relies on qualitative methods of research.

\section{RESEARCH DESIGN AND SAMPLING}

The research informing this report was conducted between November 2017 and January 2018. The study was conducted primarily through field visits to 31 schools funded by PEF in five selected districts of Punjab (see Table 4). The study employed a mix of purposive and convenience sampling to choose schools. Of the 31 schools included in the study, 19 are owned by private entrepreneurs and 12 are run by CSOs. In choosing the districts and locations, an effort was made to include schools located in the lesser developed slum/peri-urban and rural regions of Punjab that have low enrollment rates. Some of the school locations are in areas of Muzaffargarh and Multan, which the provincial government and the World Bank have identified as low-performing districts. In addition, schools from different PEF programs have been chosen to get a sense of the similarities and/or differences between them. As noted in the previous section, PEF currently has four programs-FAS, EVS, NSP, and PSSP_and the study purposefully included schools from each of these programs. Table 4 shows the location, the PEF program, and the number of schools visited in this study.

A major challenge encountered by the principal investigator was that of accessing PEF-funded schools. When contacted, PEF staff informed the researcher that it might take months and that PEF might still decline access to its schools, if it felt that the research might criticize its programs. Given PEF's lack of interest in facilitating the research, the short duration of the fieldwork, and a desire to ensure unbiased data, a decision was made to include schools funded by PEF located in various areas of Punjab that could be accessed via contacts developed independently by the researcher. A major concern was that accessing schools through PEF would compromise the data and result in biased responses from school owners. If owners perceived the researcher to be linked to PEF, the body that controls their funding, they would be less likely to share openly about their experience with its programs. 
Table 4: School locations, PEF program categories, and number of schools in the study

\begin{tabular}{|l|l|l|}
\hline District & PEF program categories & Number of schools \\
\hline Hafizabad & $\begin{array}{l}\text { EVS } \\
\text { FAS } \\
\text { NSP } \\
\text { PSSP }\end{array}$ & 8 \\
\hline Multan & EVS & \\
\hline FAS & NSP & 8 \\
\hline Muzaffargarh & FAS & \\
\hline Mandi Bahauddin & NSP & 4 \\
\hline Lahore & FAS & 7 \\
\hline $\begin{array}{l}\text { Total number of schools visited } \\
\text { per program }\end{array}$ & EVS & FAS \\
& NSP & 4 \\
\hline $\begin{array}{l}\text { Total number of schools in } \\
\text { sample }\end{array}$ & PSSP & $\begin{array}{l}7 \\
10\end{array}$ \\
\hline
\end{tabular}

At each of the selected schools, the principal was interviewed about PEF's program process and school-related information, including teachers, students, curriculum, testing, and parental participation. School owners/principals were chosen as participants because they have a school-level view of the student population, interact with the PPP programs, and can reflect on the programs' impact on their schools. The researcher used a semi-structured question guide to interview principals and other stakeholders; she addressed a standard set of themes but tailored the questions to individual respondents and contexts. The interview questions were translated into Urdu and re-worded as necessary. Observations on the physical space and facilities of school buildings were recorded as well. Officials from CSOs partnering with PEF, especially in the PSSP and NSP programs, were also interviewed.

The interview process adhered to research ethics protocols; the researcher sought from all respondents their consent to participate, having first provided them with an overview of the project and information about their rights as participants, how participating could affect them, how confidentiality would be addressed, and how information provided would be used. The researcher also offered participants the option of personal and/or organizational anonymity, and asked for permission to audio-record the interview. This was key when accessing schools funded by PEF, as school owners and CSOs were concerned about negative consequences if they were critical of PEF. Three school owners in different districts declined to participate, saying that PEF had warned them not to speak to researchers.

Focus group discussions were carried out with both female and male teachers at training sessions arranged by a local CSO for teachers from PEF schools. This was done to get the perspectives of teachers on access, equity, and quality, along with the monitoring and testing done by PEF in these schools. Trainers were interviewed and conversations took place with participants, including teachers. These sessions included teachers and principals from PEF schools from the districts of Layyah, Khushab, Rajan Pur, Rahim Yar Khan, Multan, Mandi Bahauddin, and Hafizabad. While schools in four of these districts could not be visited, it was useful to get the views of teachers and principals on issues of access, equity, and quality in PEF schools. The training sessions provided insight into some of the challenges teachers were facing in PEF schools including discussions on the syllabus, textbooks, and the Quality Assurance Test (QAT) preparation. The primary goal of the sessions was to train teachers on QAT preparation. 
In addition, other stakeholders from international donor organizations, including World Bank staff, were interviewed in Islamabad. Consultants who were involved in marking completed QAT tests and reviewing the quality of the QAT test questionnaire at a local university were also interviewed to obtain their insights into PEF's work. Furthermore, interviews were conducted with directors of major local research organizations that have focused on PPPs and have an in-depth view of PEF's programs and the wider system of education in Punjab. An effort was made to contact PEF officials and directors of the programs that were included in the study; however, only a CPDP official gave a short interview to the researcher. Despite several requests during the fieldwork, the researcher was not able to obtain an interview with PEF or government education officials in Punjab. In total, 42 individual interviews were conducted with 31 PEF school owners and 11 stakeholders, and two focus group discussions were conducted with 25 teachers (see Table 5). After the interviews, the researcher transcribed recordings and wrote up detailed notes, assigning numbers or code names to respondents to ensure personal and/or organizational anonymity. The researcher then carried out a thematic qualitative data analysis, while taking note of illustrative quotes.

Table 5: Participants interviewed in the study

\begin{tabular}{|l|l|}
\hline Interviewees & $\begin{array}{l}\text { Number of } \\
\text { participants }\end{array}$ \\
\hline Owners/principals of PEF-supported schools & 31 \\
\hline Donor organization officials in Pakistan (World Bank, DFID, UNESCO) & 3 \\
\hline PEF staff/consultants (CPDP official, PEF teacher trainers, QAT testing consultants) & 4 \\
\hline Local CSO officials/research think-tanks & 6 \\
\hline Two focus groups: female teachers in PEF schools & 14 \\
\hline One focus group: male teachers in PEF schools & 11 \\
\hline Total number of interviewees & 69 \\
\hline
\end{tabular}

\section{LIMITATIONS OF THE STUDY}

The goal of this study was to gather rich accounts related to access, equity, quality, and gender issues in PEF-funded LFPS; the researcher therefore focused on obtaining in-depth interviews with only 31 participant principals from a sample of schools in selected districts of Punjab. In addition, she included testimonies and views of stakeholders involved in LFPS funded by PEF and those with an insight into the education sector in Punjab. While the number of schools and principals included is suitable for a descriptive study, the results cannot be used to generalize the experience of all PEF-funded schools and LFPS in Punjab. In addition, due to time and resource constraints, the study was limited to capturing the views of principals in LFPS and not their counterparts in the public school system. A future research project would be to interview principals in public schools in the same province to compare the differences and similarities between schools in the two sectors. The study was also limited in gathering the views of principals and a small number of teachers in PEF-funded LFPS. It would also be worthwhile to gather the views of parents and community members regarding access to and the quality of education in LFPS in order to understand how other stakeholders view such schools. A future study that includes parents and other stakeholders may give a more comprehensive picture of the performance of LFPS. 


\section{FINDINGS}

\section{EQUITABLE ACCESS FOR MARGINALIZED POPULATIONS}

Equitable access in PEF schools was considered in relation to the number of out-of-school children, girls' enrollment, students with disabilities, non-fee-related expenditures that prevent access by the poorest children, and dropout rates among students. The definition of 'out-of-school' encompasses a wide range of realities and includes children who do not have access to a school in their community; do not enroll despite the availability of a school; enroll but later than they should; enroll in schools that have poor facilities or no teachers; drop out of the education system; and enroll but do not attend school (UNICEF, 2015).

\section{Out-of-school children}

"In PEF schools you will not find out-of-school children or the poorest of the poor. The majority that makes the student population in PEF schools is of those who can afford to pay some fees." (Interview with principal, School No. 8)

"Many kids in this area do not go to school as they work to support their families. So we do have a big out-of-school population, but PEF schools are not able to include them. School owners are burdened with the QAT and get low funding; as school owners we cannot do much in this situation." (Interview with principal, School No. 25)

A key finding of this study is that very few children who were previously out of school appear to be accessing schools in the PPP program. Of the student population of 12,502 in our sample of 31 PEF schools, the reported number of previously out-of-school children was 158 , a mere 1.3 percent. This is important, as a key goal of PEF programs is to enroll and cater to the very poorest people and out-ofschool children in the province (PEF, 2016). All the school owners interviewed acknowledged that either the majority or all of their students had come from a government or a private school. All the owners also stated that PEF did not have any requirement that the school should have a certain percentage or number of out-of-school children. They added that PEF does not check for out-of-school children in any of its monitoring visits or when students are enrolled under any of the four programs.

These findings confirm an observation made in an earlier study by Car-Hill and Murtaza (2013) that the EVS program specifically was not targeting children who were out of school. Moreover, these authors found that, while the numbers of vouchers distributed to each area were based on numbers of out-of-school children, number of schools, etc., such factors were not formally considered by PEF officials when the selection and monitoring of schools was undertaken (Ibid.). The reluctance of some principals to accommodate out-of-school children in their schools, in the absence of PEF monitoring, was indicated by the response of one interviewee for the present study: "We don't have any out-ofschool children in this school. The ones in the community don't want to study and can be a waste of our time. There are no criteria from PEF to have such children." 23

Interviewees overwhelmingly highlighted the fact that PEF schools are not catering for the large out-ofschool populations in the areas in which they operate, including both rural and urban/slum areas of Punjab covered by our sample. Children in these areas are engaged in child labor and family farming activities. Forty percent of school owners also complained that during harvest season a huge number of their students stop coming to school and instead accompany their parents to the fields. If the school owners try to force them to come to school, they drop out. PEF, the school owners say, does not 
understand this situation in the rural agricultural areas of Multan, Muzaffargarh, Mandi Bahauddin, and Hafizabad. If PEF monitors come to a school during harvest season and find low attendance levels, they penalize the owners.

Similarly, 80 percent of school owners argued that it is very difficult to teach and retain out-of-school children. Since they have not been to school, they said, it is a struggle to teach them the basics and they cannot be expected to perform in the QAT even after two years of being at school. Therefore, the majority of the school owners and principals interviewed did not want to admit out-of-school children to their schools, and they can avoid doing so, as PEF's monitors do not check the number of such students. This is concerning, as PESP III contains a goal to "expand outreach of the PEF to 2.8 million out-of-school children" (World Bank, 2016, p.5). The findings of this study suggest that PEF is not likely to be translating this goal into practice in the schools in its programs.

\section{Enrollment of girls}

"There are more boys than girls in this school. People mostly invest in their sons' education, and education even in PEF schools is not entirely free. Girls' enrollment is low and we are trying to change that by encouraging parents, but it's a village area and parents generally focus more on boys. We have no fixed spots for girls. PEF has no such requirements for enrollment." (Interview with principal, School No. 2)

The numbers of boys and girls in the PEF schools visited raise concerns that the organization's stated "preference for female education" and focus on girls' enrollment may not be a reality on the ground. The study included two kinds of school: those that were co-educational or had separate sections for boys and girls, and those that only admitted girls (and no boys) after Grade 5, or in some cases Grade 8. Of the sample of 31 schools, 20 were co-educational and 11 were girls-only.

The study found that gender parity is not being achieved in most of the schools sampled. Of schools that had both genders, 75 percent had more boys than girls, and only 25 percent had a higher number of girls. In schools that were open only for girls after Grades 5 and 8, most (72 percent) had a higher number of girls, as would be expected for this type of school. Overall, of all the schools in the sample, 65 percent had more boys, compared with 35 percent that had more girls. Although the sample for the study is small, its findings raise concerns that schools in the program may not be contributing to improving gender parity rates in the province, particularly given a lack of PEF policies or funding to target girls. Tables 6 and 7 present the different categories of school to give a more detailed breakdown of student numbers by gender. 
Table 6: Enrollment in co-educational PEF schools

\begin{tabular}{|l|l|l|l|l|}
\hline School & PEF program & $\begin{array}{l}\text { Number of } \\
\text { students }\end{array}$ & Boys & Girls \\
\hline School No. 2 & NSP & 360 & 190 & 170 \\
\hline School No. 4 & NSP & 120 & 50 & 70 \\
\hline School No. 5 & NSP & 97 & 58 & 39 \\
\hline School No. 6 & NSP & 90 & 31 & 59 \\
\hline Schools No. 7 & EVS & 694 & 416 & 278 \\
\hline School No. 9 & FAS & 1,000 & 560 & 440 \\
\hline School No.10 & FAS & 741 & 438 & 303 \\
\hline School No. 11 & FAS & 417 & 271 & 146 \\
\hline School No.12 & FAS & 900 & 500 & 400 \\
\hline School No. 13 & FAS & 450 & 210 & 240 \\
\hline School No. 14 & FAS & 1,800 & 1,100 & 700 \\
\hline School No. 17 & NSP & 135 & 68 & 67 \\
\hline School No. 19 & NSP & 37 & 17 & 20 \\
\hline School No. 20 & NSP & 76 & 36 & 40 \\
\hline School No. 21 & NSP & 317 & 190 & 127 \\
\hline School No. 22 & FAS & 500 & 265 & 227 \\
\hline School No. 23 & EVS & 600 & 350 & 250 \\
\hline School No. 24 & EVS & 400 & 220 & 180 \\
\hline School No. 25 & EVS & 275 & 165 & 110 \\
\hline School No. 26 & EVS & 400 & 240 & 160 \\
\hline Total & & $\mathbf{9 , 4 0 9}$ & $\mathbf{5 , 3 7 5}$ & $\mathbf{4 , 0 2 6}$ \\
\hline & & & & \\
\hline
\end{tabular}

Table 7: Enrollment in girls-only PEF schools (after Grades 5 and 8)

\begin{tabular}{|l|l|l|l|l|l|}
\hline School & $\begin{array}{l}\text { PEF } \\
\text { program }\end{array}$ & Students & Boys & Girls & Segregation \\
\hline School No. 1 & EVS & 790 & 400 & 390 & Girls-only after Grade 8 \\
\hline School No. 3 & FAS & 216 & 0 & 216 & Girls' school \\
\hline School No. 8 & EVS & 165 & 50 & 115 & Girls-only after Grade 6 \\
\hline School No. 15 & FAS & 1,206 & 362 & 844 & Girls-only after Grade 5 \\
\hline School No. 16 & NSP & 160 & 64 & 96 & Girls-only after Grade 6 \\
\hline School No. 18 & NSP & 135 & 54 & 81 & Girls-only after Grade 5 \\
\hline School No. 27 & PSSP & 62 & 25 & 37 & $\begin{array}{l}\text { Girls' school, now open to boys } \\
\text { up to Grade 5 }\end{array}$ \\
\hline School No. 28 & PSSP & 92 & 44 & 48 & $\begin{array}{l}\text { Girls' school, now open to boys } \\
\text { up to Grade 5 }\end{array}$ \\
\hline School No. 29 & PSSP & 123 & 48 & 75 & $\begin{array}{l}\text { Girls' school, now open to boys } \\
\text { up to Grade 5 }\end{array}$ \\
\hline School No. 30 & PSSP & 79 & 43 & 36 & $\begin{array}{l}\text { Girls' school, now open to boys } \\
\text { up to Grade 5 }\end{array}$ \\
\hline School No. 31 & PSSP & 65 & 37 & 28 & $\begin{array}{l}\text { Girls' school, now open to boys } \\
\text { up to Grade 5 }\end{array}$ \\
\hline Total & & $\mathbf{3 , 0 9 3}$ & $\mathbf{1 , 1 2 7}$ & $\mathbf{1 , 9 6 6}$ & \\
\hline
\end{tabular}

One reason why PEF schools in some areas may have more girls is reduced distance to school, as a school owner explained: "Girls enroll in PEF schools because of distance, that's the main reason. Where a government school is far away, then girls will go to the closer school. Our EVS school is considered to be a small neighborhood school. There are some parents who send their girls here, but 
they send their boys to a better private school where they pay a higher fee. You will find fewer girls in other private schools, including PEF."24

This corroborates the findings of Verger et al. (2018, p.262): "Not all poor families choose LFPSs because they consider them as superior forms of education provision. Closeness to home is one of the main school choice criteria for many poor families because it makes schooling more compatible with the parents' domestic and work duties, and because it saves money on transportation." In Punjab, as the distance to the closest eligible school increases, the drop in enrollment among girls is three to four times as great as that for boys (Andrabi et. al., 2008). This was very true of LFPS in the study sample as girls, especially in rural areas, have limited mobility and cannot travel long distances alone. Mobility and high transport costs are important factors in schooling in Pakistan, an issue that is discussed in more depth below.

School principals in the majority of the co-ed PEF schools argued that it was still a big challenge to attract a higher number of girls to their schools and that the dropout rates for girls were high after Grade 5 and in some areas Grade 8. One principal summed up the situation: "Girls often get married young. Parents don't send them to school after Grade 7 or 8 . They make them work at home and then get them married. So the dropout rate for girls is very high. For girls, enrollment is still low. Preference is always given to boys when it comes to private schools. Here in this area, ours is a non-fee school but still boys are given preference. This is because of various non-fee expenditures." 25

The findings of this study suggest that enrollment of girls is still low in many PEF schools and that dropout rates are higher for girls, consistent with the trends in many rural and urban/slum communities in Punjab. Pakistan has an abysmally low ranking on gender equality indicators, and cultural beliefs and practices tend to discriminate against girls in acquiring an education (I-SAPS, 2016). The cultural practices of early marriage and unpaid domestic work often result in girls dropping out of school early. Girls from poor households, especially in rural areas, are also more likely to marry early (UNFPA, 2012). Interviews with principals confirmed that these concerns are systemic and that they also affect girls' enrollment and completion rates in LFPS. Non-fee expenditures often act as a barrier to educating girls from very poor families (see more on this below).

\section{Students with disabilities}

"We have no children with disabilities in this school. I have kept no such children in my school. I don't have the facilities for it and I cannot hire a special needs teacher. It's all a big headache." (Interview with school owner, School No. 24)

Evidence from the field suggests that there is no reasonable accommodation for students with disabilities in most PEF schools, despite the Punjab government's recent promotion "of an inclusive education system for children with special needs" and its launch, with PEF, of the Punjab Inclusive Education Project (PIEP) in a sub-set of schools in seven districts, including Lahore and Multan (PEF, 2016). Of the sample's student population of 12,502 , the study found only 11 students who had a disability in all of the PEF schools visited, and none of these students was supported by PEF. Instead, the school owners were charging them a nominal fee to attend their school. It is important to note that while there are only a few PSSP schools in the study sample, none of them had children with disabilities, despite the fact that public schools are meant to serve all children.

In most of the schools visited, buildings are not physically accessible. In addition, none of the schools visited had a single special needs teacher. The lack of facilities for children with disabilities in PEF schools is an important finding, with the problem summed up by one principal: "We have students with disabilities at the moment. We cannot accommodate them, especially mental disability. We had two who had physical disabilities but they were not supported by PEF, they were paying fees. It's tough for schools to arrange facilities with the amount that PEF offers; it's too low and not feasible for owners." 26

The findings confirm that the lack of inclusive education is a major challenge in Pakistan, and suggest that PPP schools are not able to cater for students with disabilities in the communities in which they 
operate. Disability is a major source of educational inequality in Pakistan and "needs to be understood broadly, taking into account disadvantages arising from the intersection of disability, poverty, gender, location and other factors" (Rose et.al 2018, p.3). Although data are not readily available, a survey conducted in Punjab and Khyber Pakhtunkhwa in 2006-07 found enrollment rates to be 10 percentage points lower among children with disabilities, with lower rates of participation among young women with disabilities compared with young men with disabilities (Malik and Rose, 2015, p.4). The more recent TEACh study also shows that "private school enrollment is more likely among boys with disabilities, while girls with disabilities are more likely to be out of school" (Rose et.al 2018, p.7). It also highlights that childhood disability and household poverty appear to be related (Rose et.al 2018, p.5). Given the limited resources available in the low-fee private sector, any child who requires extra attention and facilities would represent a liability for school owners. Clearly, if the government and donors wanted to target children with disabilities, they would have to formulate a different kind of program and put in place dedicated resources and incentives for schools based on the inclusion of children with disabilities.

\section{Poor families and non-fee cost barriers}

"The poor go to the government schools in the area. They cannot afford any expenditure on education. Now PEF just gives fees and books. We as school owners cannot ensure the education of everyone and include the poorest of the poor in this school with other kids. It's not like a charity, we have limited funds from PEF and I also need to earn a livelihood from this." (Interview with principal, School No. 1)

All the school owners and teachers who participated in the study stated that, other than the fees and books provided by PEF, all expenditures had to be borne by students' parents. These expenditures include uniforms, shoes, stationery (notebooks, pencils, etc.), school bags, transport to school, and lunch. Many school principals reported that a significant number of parents also paid for private tuition (tutoring) after school. The cost of private tuition varies, but was reported to be between PKR 200 and PKR 700 per month. Based on the figures given by PEF school principals visited in the sample for non-fee expenditures, on average parents spend between PKR 14,750 (\$127) and PKR 17,300 (\$150) each year (see Table 8). With individuals at the poverty line earning an annual income of PKR 36,360 $(\$ 314)^{27}$ (Government of Pakistan, 2015), these costs for one child could represent half of the income of a parent living at the poverty line. It is clear that the poorest families cannot afford the expenditures associated with PPP schools.

Table 8: Non-fee expenditures in PEF schools

\begin{tabular}{|c|c|}
\hline Items of expenditure & Cost in PKR per year $($ PKR $1=\$ 0.0086)$ \\
\hline School uniform & $750-1,200$ \\
\hline Shoes & 900 \\
\hline Stationery (notebooks, pencils, etc.) & 2,000 \\
\hline Transport & $\begin{array}{l}6,400-8,000 \text { (depending on distance, } 800-1,000 \text { per } \\
\text { month) }{ }^{28}\end{array}$ \\
\hline Lunch & 4,000 \\
\hline Private tuition & $200-700$ \\
\hline School bag & 500 \\
\hline Total per student & $14,750-17,300(\$ 127-150)$ \\
\hline
\end{tabular}

In 45 percent of schools, primarily those being run with CSO support, school principals stated that they sometimes provided stationery and money for uniforms for students whose parents could not afford to pay for these items themselves. However, they also noted that this number was small, as they had limited funds. In these schools the researcher noticed that many children were not wearing uniforms, and she was informed that some parents had said that they would buy them after the harvest season, when they would be paid. The observations of one principal summed up this overall finding: "The parents in this area are involved in farming and work on the land. They are poor and many are not 
literate. For them, affordability is a major issue, so we say we will pay the fee. But then they still have to pay for stationery, uniform, and transport. Some students drop out because of these expenditures. Sometimes the teacher pitches in and asks the NGO to help pay for their uniform." 29

The finding that non-fee costs such as transport and school items, including private tuition (tutoring), account for a significant portion of educational expenditure borne by parents, is supported by the findings of an Alif Ailaan (2015) report. This report notes that expenditure on transportation is higher for private school students than for students at government schools and that the cost of essential school items (uniforms, shoes, textbooks, notebooks and school bags) is almost twice as high in private schools (Alif Ailaan, 2015, p.18). The report shows that non-fee expenditures also exist for those who send their children to government schools and that the problem is systemic, but we do not have estimates that could provide a meaningful comparison between expenditures in government schools and in LFPS. Results from respondents and calculations of average costs show that non-fee expenditures in PEF schools act as a major barrier to accessing education for children from very poor families. Reports from school owners also suggest that government schools are more accessible than LFPS for those who cannot pay as much.

\section{Screening and selection of students}

In 90 percent of the schools included in this study, principals stated that they administered screening tests of children when they applied for admission. Of this percentage, 70 percent admitted that they most often preferred to admit children who passed the entry test, as well as those whose parents agreed to their child being placed in a lower grade due to poor performance on the test. They reported that weak students are then subject to a probationary period so that they can reach a level where they can successfully participate in the QAT, a standardized test that is administered by PEF in all its program schools. The QAT is a two-hour exam covering four subjects; English, Urdu, Science, and Mathematics. Schools that fail two consecutive QATs lose their entitlement to funds channelled through PEF.

Sixty percent of owners admitted to refusing admission to children who had done poorly on the screening test and who applied for admission, after their names had been sent to PEF for new enrollment. The main reason they gave for refusing students was their inability to cater for those who were not funded by PEF.

One principal explained a common admission procedure: "We test children when they come for admission. After PEF has enrolled students in their system for the year, we only take a student if he/she is intelligent; otherwise we have to refuse them. We have limited space and funding. We have refused 25 parents this month alone." 30 These remarks were echoed by another principal, who stated: "Before admission we give a test. If the child performs poorly we don't admit them into the school. We do not want weak children because we have to pass the QAT and for some who come from government schools, their level is too low." ${ }^{31}$ And a trainer who was interviewed (Trainer 2) reported: "Owners want students who can pass the QAT, not weak ones, as the continued support of PEF depends on the test. Naturally, out-of-school children and those from poorer families are often eliminated at the time of admission in PEF schools."

The findings suggest that PEF schools in the sample do not have the capacity or incentive to ensure that every child who comes to them is admitted. PEF funds only a certain number of students, despite excess demand for schooling in many communities where it operates. School owners/principals have limited capacity and cannot send in applications for new enrollments after the yearly approval of students, so they skim off the best students during the admissions process, based on their ability to do well in the QAT.

It is important to note that the PSSP program is relatively newer compared to the other PEF programs and its schools seem to have had a different model of funding, which currently appears to be based on increasing enrollment; however, the QAT test is also being rolled out in PSSP schools. As Crawfurd (2018, p.9) notes, each PSSP school has a two-year contract with PEF, with renewal subject to 
adequate performance on the QAT. Though few in number, the PSSP schools in the sample reported similar student selection practices as schools in the other programs, as well as similar pressures of preparing their students for QATs. This suggests that PSSP schools see student selection as inherent to the PEF program, or that they anticipate having their funding tied to test scores in the near future because of PEF's model. Given that PSSP schools have taken over government schools, which are supposed to serve all children, this is particularly troubling.

\section{Selection of students in EVS schools}

In the EVS program, which is intended to target children from poor families, it is not PEF but the school owners who determine which child can apply for a voucher. Owners/principals in EVS schools stated that they did not necessarily look at the household or parental income of each child when they came for admission, and that in fact the families of many students who were receiving vouchers could afford to pay the fee. As one school principal explained: "School owners nominate students. We judge their financial situation. Then PEF comes to verify these, and they select a day and if the parents come then they are given the voucher. Of course we need to have a certain number of students too, so we cannot be too strict about the income level of parents. I think a lot of them can afford a fee but they do end up saving that money, so it's OK." ${ }^{2}$ Another said: "The criteria for the voucher are that they need to have an ID card, a phone number, and the birth certificate of the child. There are no other criteria on household income or salary of the parents, or anything related to age or gender." 33

This particular finding suggests that, while PEF aims to cater to poor households in rural and slum areas, it does not ensure in its process for awarding vouchers that those who access these schools come from marginalized and low-income households.

\section{Fee-paying students in EVS schools}

In all the EVS schools in the sample (seven out of 31 schools), principals and owners reported that they charged a fee for a year and then sent the child's name to PEF to apply for a voucher. This gave the owner time to determine whether the child would stay in school and would not drop out, as that would mean PEF cancelling the voucher and the school losing the funding for that child. In EVS schools in particular, some of the students are paying a fee, in addition to those who are funded by PEF. Many are doing so in the hope of getting a voucher the following year when PEF asks for new enrollments. This is a common practice in many PEF schools, but it raises questions about equity and the exclusion of those who cannot afford to pay a fee for the year. It also suggests that, in EVS schools at least, paying the fee might be an unofficial requirement for getting a voucher.

Reflecting on the overall situation, one principal reported: "We have 600 students, of whom 385 are funded by PEF; the rest pay a fee of between PKR 500 [\$4.30] and PKR 800 [\$7.00]." ${ }^{44}$ Another explained: "We have 790 students. PEF gives vouchers to 550 of them. The remaining ones pay a fee starting at PKR 250 [\$2.60] and going up to PKR 800 [\$7.00], and we charge PKR 400 [\$3.50] as an admission fee when they join. Then after paying the fee for a year, we send their names to PEF for new enrollment. That way we know that the child will stay in our school. Similarly, it's a way for those children who do poorly in the admission test to catch up after we place them in a lower grade. For a year they pay the fee and have time to improve enough to be able to do the QAT. Our business is based on this." 35

In summary, school owners in EVS schools in the sample are using fees to determine whether a child will stay in their school and, secondly, the fee is charged for a probationary period of a year, during which time a child who is placed in a lower grade can improve sufficiently to pass the QAT. This suggests that in EVS schools, owners are serving their own interests by obtaining PEF funding and ensuring that they do not lose any vouchers due to dropouts, as well as by having students who are able to pass the QAT. However, this can exclude children whose parents cannot afford to pay the fee for a year in order to apply for the voucher, which means that schools are unlikely to be serving the poorest and most marginalized children. 


\section{High dropout rates}

A significant problem reported by owners/principals and teachers across schools in all four PEF programs - but EVS schools in particular-was high dropout rates among students, especially girls. In total, 90 percent of principals across the four programs said that retention was a major issue for them, and that students dropped out for various reasons. Teachers from various districts who took part in the training sessions and focus group discussions also raised the issue of high dropout rates in their schools and the absence of students in the sowing and harvesting seasons.

One principal described the issue as follows:

"If you observe, PEF has a target of enrolling so many thousand kids this year. Now what about the thousand or so PEF schools that have failed in tests or which are being closed due to high dropout rates: whose responsibility are those schools? Why don't we hear about the rate of failure and the number of schools that have been cancelled [from the program]? PEF is not taking responsibility for the failure of those schools and the children who have been affected. Are the children in those schools not worthy of receiving PEF support for their education? The rise in enrollment numbers doesn't give you a complete picture of education in different districts of Punjab as we don't know the dropout rates. The biggest issue in communities like ours is the dropout rate, especially for girls: of 100 girls in primary, only 20 get to Grade 8. Eighty percent drop out in secondary and high school." 36

Another echoed these concerns: "We have a high dropout rate. Kids leave in Grade 5 especially; some transfer back to the government schools. In this area children move from one school to another and it's a problem as it affects their education-they don't learn well." 37

The issue of high dropout rates in PEF schools is often ignored by PEF officials, by the provincial government, and by donors including the World Bank, who portray the PPP initiative as a success story of reform. The findings of this report show that this is a serious concern, however, and one that needs to be investigated further to evaluate the workings of PEF schools and their overall impact on completion of education and student retention in the province.

\section{QUALITY OF EDUCATION}

The World Bank argues that the PPP initiatives in Punjab, through PEF, have generated large and rapid gains in both enrollment and learning achievement (World Bank, 2016). PEF, in its own reports, bases its growth on its increasing enrollment numbers, as well as the percentage of children passing the QAT in schools signed up to its programs (PEF, 2016). However, test scores do not provide a complete picture of the quality of education in LFPS and it is critical to look at other factors that affect the quality of education, including physical facilities and school environment, the effects of a highstakes testing system, private tuition taken by students, and teachers' qualifications and training.

\section{Physical facilities and learning environment}

"We are poorly resourced. We have incomplete furniture and not all kids even have books, so they have to share. We don't have chart papers for activities or markers for the white board. Initially we tried, but now we lack the supplies to make charts, etc. We are now trying to get a few more rooms constructed with a loan." (Interview with principal, School No. 4)

Of the schools visited for the study, 85 percent were located in congested urban/slum or rural settings. Three schools in Multan had only temporary straw roofs to shield students from the sun. Only one school in the whole sample had an open field where children could play. None of the schools had a library or a computer lab. Three had laboratories, but only because these were required for their high school students. 
It is important to note that in the five PSSP schools, which are being run in government school buildings, facilities are spacious, have boundary walls and are painted. The private owner in some cases is required to add some facilities, but in the schools visited that was not the case.

In terms of furniture, 43 percent of school owners reported that they did not have a bench for each child and that children were sharing benches and desks, where they were available. In 45 percent of schools visited, children were sitting on the ground on straw mats. This was more pronounced in schools in the NSP and PSSP programs that were being run by NGOs.

PEF monitors primarily come to check classrooms and washrooms in a school, and they often penalize owners on physical infrastructure. According to owners surveyed, PEF requires that schools have at least one washroom for every 70 students enrolled. It also requires separate washrooms for boys and girls. Most schools visited in the sample did have separate washrooms for boys and girls, but some did not have enough washrooms for all their students and were not meeting the 70:1 ratio guideline. PEF also requires that each classroom should be able to seat 35 students. In some schools in the study sample, classrooms seemed very small and crowded with 35 students. School owners reported that they usually conducted exams and tests in open spaces or on the verandas (roofed porches) of the buildings, where there is more light and space.

Despite broad guidelines, schools still lack basic facilities such as libraries, computer labs, and an adequate number of permanent classrooms. The researcher observed that most schools in all four PEF programs lacked space where children could play and that classrooms seemed cramped and dimly lit. Some 85 percent of school owners argued that they did not have sufficient funds to meet their basic infrastructure needs and that PEF ought to provide them with grants for building and furniture needs. Ten percent of school owners stated that they had taken out loans to build rooms and physical facilities in their schools and that they had gone into debt in order to provide basic facilities. A few owners also reported that they were aware of bribes being paid by some schools to obtain PEF approval for buildings that did not meet its criteria for classrooms and washrooms.

Teachers in a focus group discussion held at a training session in South Punjab also voiced concerns about lack of space and seating arrangements in PEF schools. One said: "We do not have proper seating places for kids in our schools. There is no play area. You cannot just make them study the whole day, they are kids who need to move about and play as well. But these buildings are not for schools." ${ }^{38}$ (Teacher, focus group discussion 2)

A lack of space, a shortage of teachers, and an insufficient number of classrooms result in children being taught in multi-grade classrooms; this was observed in 45 percent of the schools visited. The constraints were described thus by one principal: "Our school building is a village dwelling with four classrooms and one veranda. Two classes, Grades 5 and 7, sit on the veranda, and two classes sit in each room. PEF's rule is that per room you should have 35 students; they could be from different grades. Sometimes it's hard to have multiple classes in such a small space and we have to constantly yell at students to be quiet." 39

On the whole, the study finds that many schools in PEF programs do not have the infrastructure or materials needed to create a good environment for education and learning. Contrary to the arguments often used by proponents of PPPs that they create greater efficiency and maximize private resources, the findings suggest that low levels of investment simply lead to poor conditions. In terms of the physical facilities in PEF schools, their current condition appears to be far from achieving the "highquality infrastructure" goal of the Government of Punjab in PESP III, as supported by the World Bank and DFID (World Bank, 2016, p.5). 


\section{Curriculum, learning, and the Quality Assurance Test (QAT)}

"Accountability works. Schools threatened with losing access to subsidies almost always managed to raise student scores to meet the minimum pass rate needed to keep the funds... The threat of losing the money pushed schools to ensure better learning, as measured by the minimum pass rate on the achievement test. As the Pakistan evaluation shows, sometimes the "stick" works." (World Bank, 2012)

"Quality is a sensitive issue. The system in PEF schools, the syllabus we have to follow is all based on rote memorization. We are teaching to the test. You teach your kids the QAT format and practice on past paper guides being sold in the market. There is no conceptual learning taking place in the schools. I don't think quality is a goal of PEF, they are only concerned about enrollment and data on that to show numbers." (Interview with principal, School No. 3)

While the World Bank views the high-stakes QAT system as producing more learning based on test pass rates, school owners and other stakeholders interviewed for this study argued that it results in "teaching to the test" and rote memorization, rather than improving the quality of education in their schools. Principals of PEF schools, teachers, trainers, and other stakeholders painted a very disappointing picture and pointed to the lack of quality education. Of the school owners in the study, 95 percent argued that the QAT was a tool used by PEF primarily for its own monitoring and evaluation of schools and that its results did not measure quality or learning. All PEF school owners and teachers agreed that their main instructional technique was rote memorization and then preparing students for the test, using the test format from past papers. One principal spoke for many of those surveyed: "I think QAT is just a tool that PEF uses for its own ease. I mean, think about it, you are testing Grades 2, 3, and 4. At that level it's tough for children and the stress that comes with testing is not good for the child. I don't think it's a good way to judge learning either. It's all rote memorization; you are pushing them towards that and not really making them understand what they read. Sometimes a child knows a lot but they cannot perform in the QAT." 40

\section{QAT: Using high-stakes testing as a sole criterion of quality}

Principals, teachers, local CSO staff, and other stakeholders stressed that QAT had become the sole criterion for success and for continued funding of PEF schools, and that this was creating problems. One principal said: "The QAT is a big stress for every school, it robs us of our sleep. Schools are naturally teaching to the test. Publishers have started making booklets of test papers, that's also a good business. So now studies in PEF schools are limited to preparation of the QAT. Teachers are only teaching those units that will be tested in the QAT. If you test the child on anything other than the QAT they will fail to perform. So you cannot make the claim that learning is happening or that we at PEF-funded schools are giving quality." ${ }^{41}$

A consultant/researcher interviewed for the study expressed a similar opinion: "With QAT it means you are teaching to the test. This system has been an issue in developed countries such as the USA. With the QAT, as with other kinds of testing, you prepare students to pass multiple-choice questions and other types of objective questions that require lower skills of recall. Now you are doing this at the cost of higher-order thinking questions."

An official with a research organization meanwhile observed: "Private school owners who work with PEF say that the going rate for getting one of the top rankings in QAT and the Punjab Examination Commission (PEC) exams is PKR 50,000 (\$432). If you set up high-stake incentives, you will get such a situation for sure. That is the problem with the way we have conceptualized monitoring and evaluation over the last 10 years."

This study illustrates how the high-stakes nature of QAT, as used by PEF, appears to have created perverse incentives that are leading to undesirable outcomes, such as classroom and instruction practices that reduce learning to content measured by the standardized test. It also suggests that some schools may be gaming the system by using bribes, which raises issues in terms of both quality and equity. 


\section{Curriculum and test quality issues raised by teachers, principals, and trainers}

Some of the problems inherent with the QAT were described by a school principal interviewed for the study: "We have understood now that QAT is everything and the future of the school depends on the results of that. We are trying to teach to the test. But there are many issues and my teachers struggle. If you look at the syllabus, we don't think it's appropriate, it's not according to the level of the child. They are testing certain things that need to be tested in a higher grade. This is not the educational standard in a rural area. Now also think about the teacher who has done only matric (Grade 10)-how will she understand and teach the content herself, let alone teach it to very weak students?"42

Moreover, a majority of the school owners/principals and teachers complained that the results of the QAT were presented as an aggregate percentage for the school, with no breakdown in terms of how each student performed in the various subjects on which they were tested. School owners reported that this lack of information made it hard for them to improve their performance in the next test cycle and that they could not tell how well their students had actually performed or what areas led to failure in the QAT for a school. For them the percentage had little meaning other than whether the school had passed or failed and would continue receiving its funding. One principal stated: "They announce the result by putting a percentage that the school got and that's all that we know. PEF should give us the detail of these test results. We are partners, right? We, principals and teachers, should know how each child did. I don't know what a 90\% means, it just means that we passed."

In addition to pointing out the limitations of the QAT as a tool for evaluating quality in PEF schools, 35 percent of principals, and a majority of teachers and trainers interviewed, argued that the syllabus being used had not been formulated to take account of the learning levels of children in different grades. They also stated that an average PEF schoolteacher, with only a Grade 10 or 12 education and no training, often found it challenging to teach this syllabus to students.

A trainer stated: "I conduct trainings for teachers in PEF schools and I am running a chain of schools that has done well in QAT results. But the books that we are using in PEF schools are faulty; it's a poorly designed syllabus. They waste the child's first two years with the content that is provided. And then when the child transitions to Grade 1, the level and skills required are ones that the child hasn't been prepared for in the earlier years." 43

As well as the syllabus used in PEF schools, interviewees pointed out the poor quality of the QAT as a test. A CSO consultant/researcher said: "The quality of the QAT test is very poor; [we could say] lower than poor. The validity and reliability of the test items were questionable. We were not allowed to include in [our] report that the quality of the test was poor. We put everything in the report, but I do not know which reports are passed on and which ones are buried. They say that if this report goes to the World Bank or DFID, the funding will be stopped."

A representative from a research organization concurred: "The QAT and other standardized tests in the province are very poorly designed because we do not have psychometric experts. These are useless exams with a useless process. But because it is so competitive now it is a high-pressure exam for the children, because the schools' funding depends on it. The entire system is of a very poor quality."

These findings suggest that PEF programs may be providing schooling but that learning is seriously constrained in these schools. The whole system is based on offering private school owners incentives to improve the quality of education on the basis of increased enrollments and children passing the QAT. In order to prepare for the QAT, schools rely on rote memorization and teaching to the test. The system is designed in such a way that "quality" is limited to test scores, and this is highly problematic when assessing learning in such contexts. The opinions expressed in the interviews show that the way in which academic performance in PEF's programs is measured is actually having a paradoxical effect and reducing the overall student learning achievement; this is consistent with the findings of van Thiel and Leeuw (2002). Schools and teachers are focusing on performing well only in test-based measurements such as the QAT, rather than on the actual quality of education. Furthermore, with only a limited number of performance indicators for the programs, such as only using the QAT, this means 
that not all aspects of high-quality education are necessarily being measured-such as the quality of teaching, the curriculum, learning materials, the environment, and so on.

If increasing both quality and equity in education is the objective of the PEF program, then the incentives being used currently are creating a conflict between equity and quality, and they seem to be failing to adequately address either. As school funding depends on how well students perform on the QAT, private schools are attempting to accept only high-performing students, thus reducing equity. If a school attempts to increase equity by accepting disadvantaged students who might not perform well on the QAT, it will risk losing its funding from PEF and hence will have fewer resources to support the provision of a high-quality education.

\section{Prevalence of private tuition}

"[About] 70 percent of my students take tuition after school. All my teachers teach private tuition." (Interview with principal, School No. 24)

In the interviews, 70 percent of school principals reported that a significant number (between 60 percent and 95 percent) of their students took private lessons after school. They noted a rise in this trend in both rural and urban/slum areas, across all PEF program schools. One said: "Almost all the kids in my school take private tuition after school. In fact, we provide them with tuition in the school premises. They pay separately for that, ranging from PKR 200 to PKR 700 per child. Parents are more particular about sending their children for tuition as they pay for that separately, unlike regular school where they are getting a voucher." ${ }^{44}$ Another observed: "The majority of students in my school are taking private tuition after school. Most of my teachers are giving private lessons to their own students. For them it's a way to supplement their income. We allow them to do it." 45

The prevalence of private tuition in PEF schools raises some important questions about quality, learning, and the assessment of school performance. Firstly, with private tutoring so widespread, how is the QAT able to measure school performance accurately without taking tuition into account? Secondly, it calls into question the quality of education in PEF schools, where children are probably not being taught adequately in the first place if their learning needs to be supplemented by private lessons. Thirdly, it raises big questions about equity, as lower-income students and girls are likely to be disproportionately excluded from receiving private tuition, as it is an added expense for parents. The ASER report for 2016 notes: "The incidence of private tuition remains higher in private school students compared to government school students. Overall private tuition in private schools is $33 \%$ compared to $15 \%$ in government schools" (p.186). The impact of private tuition is a crucial factor to consider when assessing the performance of children in public, private, and PPP schools in learning assessments and tests. It is also important to look at the impacts it has on equity for lower-income students and for girls, who are likely to be disproportionally excluded from this service.

\section{Teachers, gender and qualifications}

In the PEF schools visited for this study, it was observed that about 88 percent of teachers were female and only 12 percent were male. This is not surprising as LFPS in various contexts, including in Punjab, are known to rely on a large and predominantly female teacher workforce (Andrabi et al., 2011).

In terms of qualifications, 45 percent of teachers in the sample had a Grade 12 qualification, 12 percent had a Grade 10 qualification, 36 percent had a Bachelor's degree, and only 6 percent had a Master's degree. This corroborates earlier findings on teachers in LFPS which show that the average LFPS teacher has a Grade 12 qualification (Alif Ailaan, 2014; Afridi, 2017). Table 9 presents data on the gender and educational qualifications of teachers in the PEF schools included in the study. 
Table 9: Gender and qualifications of teachers in PEF schools

\begin{tabular}{|c|c|c|c|c|c|c|c|}
\hline School & Teachers & Female & Male & Grade 10 & Grade 12 & BA/BSc & MA/MSc \\
\hline School No. 1 & 28 & 28 & 0 & & 18 & 8 & 2 \\
\hline School No. 2 & 11 & 5 & 6 & 3 & 5 & 3 & \\
\hline School No. 3 & 15 & 14 & 1 & & 10 & 5 & \\
\hline School No. 4 & 3 & 3 & 0 & 1 & 2 & & \\
\hline School No. 5 & 3 & 3 & 0 & 2 & 1 & & \\
\hline School No. 6 & 2 & 2 & 0 & 1 & 1 & & \\
\hline School No. 7 & 35 & 35 & 0 & 10 & 15 & 8 & 2 \\
\hline School No. 8 & 10 & 9 & 1 & & 2 & 8 & \\
\hline School No. 9 & 35 & 30 & 5 & & 8 & 25 & 2 \\
\hline School No. 10 & 25 & 21 & 4 & & 7 & 17 & 1 \\
\hline School No. 11 & 18 & 17 & 1 & & 16 & 2 & \\
\hline School No. 12 & 30 & 28 & 2 & 7 & 11 & 9 & 3 \\
\hline School No. 13 & 20 & 16 & 4 & & 10 & 8 & 2 \\
\hline School No. 14 & 60 & 45 & 15 & & 20 & 33 & 7 \\
\hline School No. 15 & 50 & 35 & 15 & & 27 & 20 & 3 \\
\hline School No. 16 & 10 & 9 & 1 & 3 & 4 & 2 & 1 \\
\hline School No. 17 & 5 & 5 & 0 & 4 & & 1 & \\
\hline School No. 18 & 4 & 4 & 0 & 1 & 2 & 1 & \\
\hline School No. 19 & 2 & 2 & 0 & 2 & & & \\
\hline School No. 20 & 3 & 3 & 0 & & 2 & 1 & \\
\hline School No. 21 & 18 & 18 & 0 & & 6 & 7 & 5 \\
\hline School No. 22 & 18 & 18 & 0 & & 10 & 8 & \\
\hline School No. 23 & 26 & 23 & 3 & 6 & 18 & 2 & \\
\hline School No. 24 & 21 & 20 & 1 & 9 & 7 & 4 & 1 \\
\hline School No. 25 & 17 & 16 & 1 & 7 & 9 & 1 & \\
\hline School No. 26 & 14 & 14 & 0 & & 10 & 4 & \\
\hline School No. 27 & 3 & 3 & 0 & 1 & 2 & & \\
\hline School No. 28 & 2 & 2 & 0 & & & & 2 \\
\hline School No. 29 & 4 & 4 & 0 & 1 & 2 & 1 & \\
\hline School No. 30 & 3 & 3 & 0 & & 2 & 1 & \\
\hline School No. 31 & 2 & 2 & 0 & 1 & 1 & & \\
\hline Total & 497 & 437 & 60 & 59 & 228 & 179 & 31 \\
\hline
\end{tabular}

\section{Salaries}

"Low-cost private schools pay their teachers less, but get more out of them." (World Bank, 2012 c)

"The salaries of teachers in PEF schools are very low-everyone knows that. PEF should pay our teachers and then we can talk about some qualified teaching here. The issue of a high turnover rate of teachers affects us badly. Teachers who get better jobs leave us. This is also not good for the children, it affects their education. A new teacher takes time to adjust and so we bear the consequences of that. Many of my qualified teachers leave to teach in government schools that have a better salary and benefits." (Interview with principal, School No. 9)

It is interesting to note the contrast in the two statements above about teachers' salaries. While the World Bank views low salaries as beneficial in terms of reduced costs in the LFPS sector and 
increased efficiency in teachers' work, the school principals interviewed for this study pointed out that low salaries are a problem that is negatively affecting the quality of education in schools. As part of the research, school owners and teachers were asked about the salary that teachers receive each month. From the salary ranges provided by school owners, the researcher calculated the average monthly salary of a PEF schoolteacher to be PKR 6,000 (\$52). Salaries varied between schools, with some starting as low as PKR 1,500 (\$13) and one school owner paying PKR 15,000 (\$130) to one teacher. What is important to note is that the large majority of schools sampled are paying their teachers a salary that is far below Pakistan's minimum wage of PKR 15,000 (\$130).

Moreover, there is a wide gap between the salaries of government schoolteachers and those in the low-fee private sector. These differences are longstanding. Survey data from 2011 revealed that "the average monthly salary of a primary school teacher in rural Punjab is PKR 17,000 (USD 147) as compared to PKR 3,800 (USD 33) earned by their private school counterparts. This salary is roughly more than six times as much as the average per capita monthly income of the average person in Punjab. This is likely to be an underestimate of this multiple as this latter figure includes the earnings of urban workers" (Aslam et al., 2011). A more recent study by Bau and Das (2017) notes that there is virtually no overlap between public and private sector salaries, with the average public sector teacher making approximately five times as much as the average teacher in the private sector.

Figure 1: Salaries of teachers in sampled PEF schools

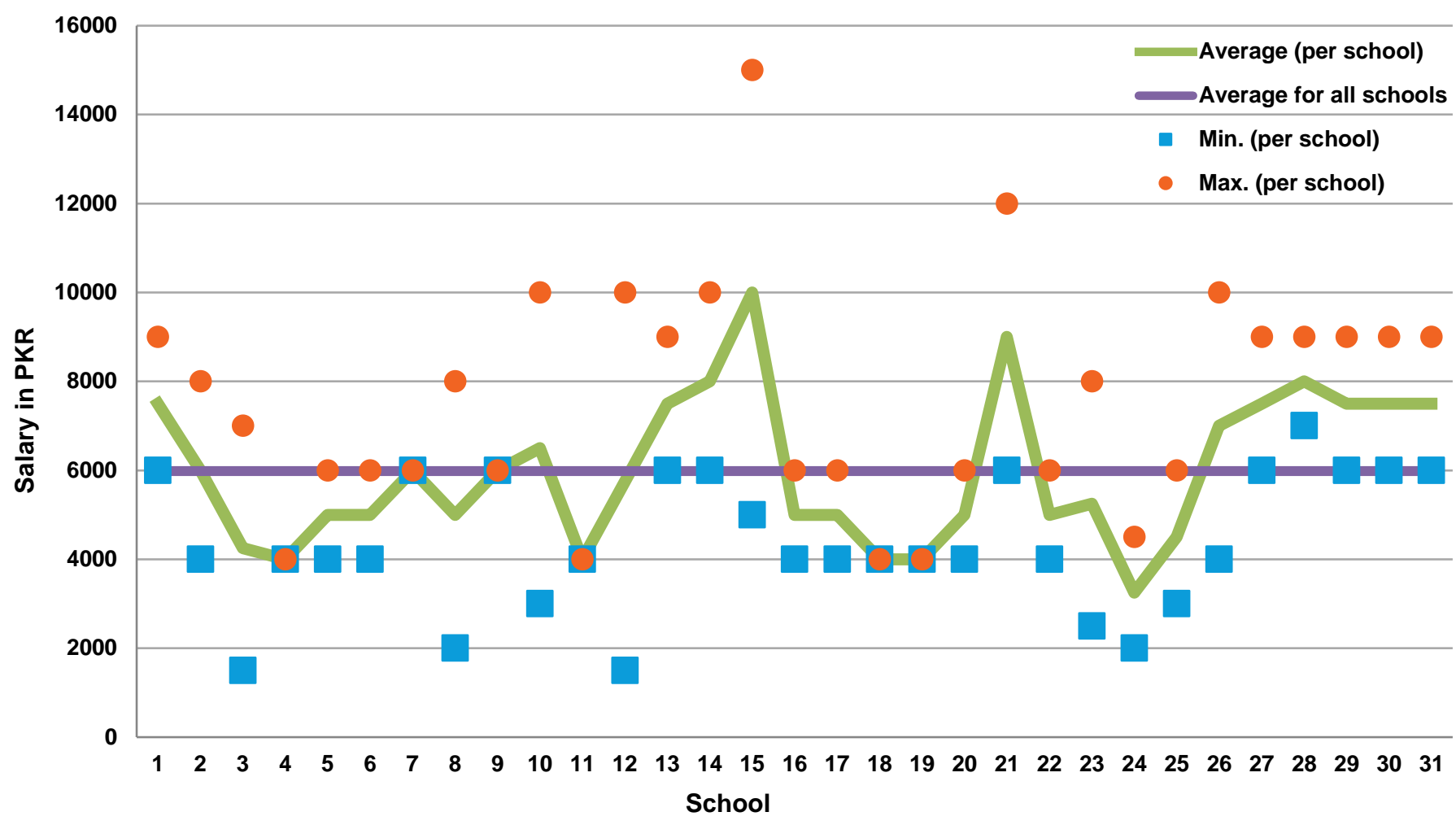

Source: Data from interviews with school owners/principals

Principals, teachers, and other stakeholders who participated in this study all agreed that teachers were being paid far less in PEF schools and that this was a violation of their right to decent work. One principal said: "In PEF's system it is the teachers who sacrifice the most. I cannot pay a decent salary to my teachers. I cannot hire male teachers, as they demand a higher salary. Females have fewer options for work." ${ }^{46}$ Another stated: "With these under-qualified and untrained teachers we are struggling. The salary we are giving them will eventually make them quit." 47

Almost 90 percent of the principals and teachers surveyed highlighted a high turnover rate of teachers as a problem in their schools, and linked this to low pay. A principal stated: "PEF doesn't care about teachers. Why don't they hire them and pay them? Why don't they set a salary based on teacher's qualifications and train them? Our teacher turnover rate is very high. They leave because of the salary we are paying." 48 
Female teachers taking part in focus groups were also vocal about the issue of low salaries in PEF schools. One said: "The salary we are getting is too low and this is the biggest problem for us. How can a salary of PKR 4,000 [\$34] be enough each month? Sometimes we have to buy stationery and cleaning supplies for the school from our salary."

This study highlights the plight of a large population of female teachers who are employed by LFPS. Women are being paid less on account of their gender, their limited mobility, and their low rates of participation in the labour market, and the whole LFPS model is based on this situation in the labour market. These findings suggest that the Government of Punjab could be violating its minimum wage legislation by not ensuring that teachers in PEF schools are paid a minimum wage.

\section{Teacher training received from PEF}

"We haven't received any training from PEF. They are quick to demand things but they don't provide us with anything and they don't help or facilitate us teachers. They will complain that the school doesn't have this or that, but they don't care how teachers are doing their work. If children pass the QAT, they think that teaching and learning is taking place. As a teacher, I don't think this is correct. The QAT doesn't tell you much about the quality and standard of education in these schools." (Interview with teacher, School No. 20)

The findings of this study suggest that, although most teachers in PEF schools have low qualifications, the opportunities they have to receive any training are few and far between. About half of school owners reported that they had not received any teacher training from PEF in the past five years; 23 percent said that two or three of their teachers had received PEF training once in that period, and just three schools reported that two or three of their teachers had received training from PEF more than twice in the past five years. A few schools run by CSOs have managed to provide training to some of their teachers at least once privately. Figure 2 summarizes the findings.

\section{Figure 2: Training received by teachers in PEF schools in sample in the past five years}

\section{Number of schools, from total sample of 31}

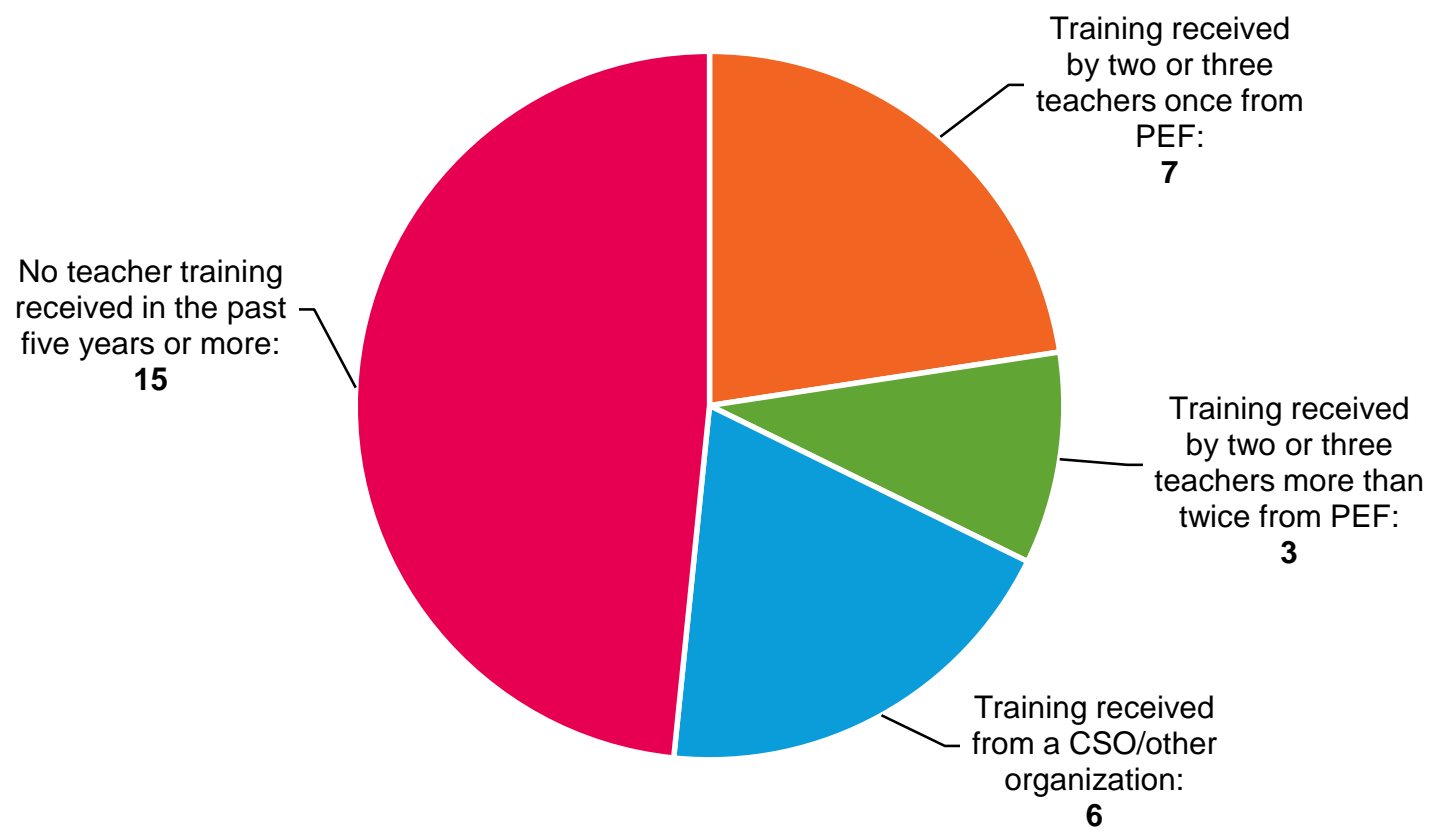

Source: Data from interviews with school owners/principals.

Teachers who participated in the study voiced concerns that having to teach multiple grades without any training made their jobs difficult. It is important to note that multi-grade teaching is a common practice in primary-level schools across the country, and is generally carried out by teachers who are 
untrained in how to manage classrooms with children of different abilities (Aslam et al., 2011). One study found that multi-grade teaching was being practiced in 22 percent of government-run rural schools and 11 percent of urban schools in Punjab. In multi-grade schools, on average one primary teacher was teaching three grades or more (Bari et al., 2013).

One teacher reported: "We struggle a lot with multi-grade teaching. The whole day passes teaching one class after the other. At times, it seems hopeless. There is so much pressure from the QAT. We are stressed because we will be answerable if the result is bad. We are the ones who will be blamed." ${ }^{49}$ Another teacher remarked: "Multi-grade teaching is very difficult with these children. It's very noisy as well. We teachers feel that we need training, especially for such things. Our job is very difficult and we feel that PEF is completely ignoring the plight of teachers in their schools. We are still supported by an NGO that tries to give some training, otherwise we'd probably leave our jobs here." 50

Owners/principals of PEF schools also acknowledged the lack of training and voiced concerns about the expectation that they should bear the responsibility and expense of training their teachers themselves. One principal said in an interview: "It's up to the owner to train his teachers. That's an additional burden no private school owner wants to take. PEF has a whole department for this... They are supposed to be facilitating and training teachers. For the school owner, it's not easy to perform well in the QAT with teachers who have a Grade 10 education and no training. People in the CPDP are not connected to the field or to schools in the districts. They don't understand the context our teachers work in. They don't know why enrollment is low and dropout rates high." ${ }^{1}$

These observations were backed up by a teacher trainer, who told the interviewer: "I agree PEF doesn't conduct any trainings for teachers. The training that they do is irrelevant and ad hoc. Let's not talk about quality; we are not even touching quality of education in PEF schools. We are just delivering results in exams. We in PEF schools tie teacher performance and quality to QAT results. Don't the government and PEF know what the minimum wage is? Don't they know that none of the teachers in PEF schools are getting that? With the PKR 550 per child, how can you pay a decent salary to your teachers? What about the money you need to spend on training? How can you expect private school owners to do this?"

The findings of this study call into question several aspects of the rationale for PPPs in education. PPPs involving LFPS are sold as cost-effective, and it is claimed that they get better results for less money. However, in the case of PEF schools, owners argue that with the funding they receive, which ranges from PKR 550 [\$4.70] to PKR 900 [\$7.80] per child, it is unfair to demand that they provide better facilities or spend more on teachers' salaries. Although the assumption is that private sector owners will be incentivized to provide teacher training themselves, the findings suggest that in reality private owners are not providing proper training to their teachers due to the associated cost. Moreover, they are unhappy that they are expected to bear the costs of teacher training themselves, given that PEF provides only a small amount per child that does not cover additional expenses. Interviewees argued that, with the current level of funding provided by PEF, they could not be expected to do any more. Education is an investment, and the findings suggest that Punjab's PPP program is not making the investment needed to achieve quality education.

Moreover, the few schools that did acknowledge receiving training from PEF found that it was not very useful for their teachers. One principal said: "PEF training for teachers is not targeted for the children we need to deal with, children who are weak and have poor backgrounds. PEF's training is for children in posh schools and areas. But our students are not like that. So how can our teachers apply their methodologies, etc. in this school? We keep saying this but no one listens. The teachers struggle the whole year and the dropout rates are high." 52

Another said: "Once a couple of teachers from my school went to attend a PEF training. But if you ask me, that training is useless. At the end of the day teachers do what they want and feel it is easy for them. The goal is the test; as a teacher, you need to ensure students do well, I am not concerned how you teach or do it." 53 
These findings illustrate a major flaw of PEF's program more broadly: that it is not grappling with the underlying problems of poverty faced by both children and schools. Instead of a needs-based model that resources schools according to the needs of students and teachers, the incentives model leaves schools to figure it out for themselves. PEF's ad hoc and infrequent teacher training is not effective as it does not address the challenges that they face in the context of limited resources, children from poor backgrounds, and multi-grade teaching without any support. The CPDP official acknowledged that training was generalized and not formulated for teachers dealing with such challenges. Given that a significant portion of the PEF budget is used to fund CPDP and the World Bank has also emphasized professional development for teachers in the province, PEF needs to evaluate its teacher training. It is apparent that teachers in PEF schools have an acute need for frequent training but that PEF does not provide regular training for all teachers, even on a yearly basis. With further expansion of PEF's schools and programs, the challenges of training a large teaching workforce will only grow more severe.

\section{School funding and resource levels}

All of the principals and teachers interviewed reported that the monthly disbursement of grants to PPP schools was usually delayed and that this puts the schools under severe financial pressure, resulting in delayed salary payments to teachers and affecting the delivery of education. Interviews with principals also illustrated that PEF partner schools receive very low overall levels of resources and that this has a negative impact on education quality, leading to low teachers' salaries, an inadequate learning environment, and insufficient materials, training, etc. For example, in the Foundation Assisted Schools Program, schools receive per student monthly funding of PKR $550(\$ 4.73)$ at the primary level, which rises to between PKR 700-1100 (\$6.02-\$9.46) for secondary depending on the level; other PEF programs appear to have similar per student funding levels (PEF, 2016).

One summarized the situation as follows: "PEF usually delays its payments to us. School construction is very costly. PEF does not facilitate us. We have spent so much on furniture for classes. I have developed this school on my land, which is an asset for this community; I have done this with loans. I hope at some point I will be able to pay these off. PEF is also not increasing the number of kids who they fund. The private sector schools in PEF are providing education with a very small amount of money compared to government schools that are well funded. How can you expect quality to come in that? We are merely surviving and doing our best in the hope that PEF support continues." 54

Another said: "This is an open school. We have no electricity. They complain that you need more toilets. Sure we do. But where are the funds for it? PEF doesn't pay for anything except the PKR 550 per child. With that, we have to pay the teachers and pay rent for this space. They also cut money by penalizing us. We can't bear additional expenses within the amount they give." 55 However, a third said: "There is a lot of savings for those schools that have a large number of kids supported by PEF [...] For some owners it's a sweet deal. If someone has 1,200 students, calculate it and you get PKR 8 lakh $[\$ 6,919]$ per month. Expenditures are less than PKR 4 lakh $[\$ 3,459]$. So you save PKR 4 lakh per month." 56

Another principal took a wider view: "Quality is an issue in this country as a whole, but probably more so in this LFPS sector. I don't think we are providing a quality education, and I don't think the focus is on quality at all. PEF itself is concerned with the number of enrollments. If they can show numbers, they will call it successful educational reform. But we know that the quality is not there. You cannot give quality on PKR 550 [\$4.73] per child. You cannot give quality with teachers who have only done Grade 10 or 12 themselves and have zero training opportunities. No owner can invest in training, and nobody does." 57

These findings raise questions about the key claims made for PPPs—that they are more cost-effective than other options and that they provide better value for money. The interviews demonstrate that cost savings come at a high price, and that schools are sacrificing quality due to a lack of investment in education. 


\section{DEMOCRATIC AND SOCIAL ACCOUNTABILITY}

An earlier section discussed the notion of test-based accountability based on the QAT in PEF schools; this section looks at the democratic and social accountability of PPP schools and of PEF to local communities.

\section{School Management Committees and parental participation}

The lack of perspectives from parents and students in this study is a major limitation when considering School Management Committees (SMCs) and parental participation; it should be borne in mind that principals and teachers may display a degree of bias in how they view parents and their participation (or lack of it) in schools. However, feedback from owners/principals and teachers does give important insight into the lack of structures available for parental engagement and oversight in PPP schools.

Most significantly, all the school owners interviewed acknowledged that their school had no SMC or committee in which parents participated. One principal said: "I think parents and community members don't have a good understanding of education, nor can they make a distinction between the quality of education in various private and public schools. There are no SMCs here, [though] those are important to create any participation at community level. In private and PEF schools there is no concept of any such committees, not even on paper." 58

On its website, PEF states: "School's Parent Teacher Council should be made and in case of field/recreational/trips/activities consent of parents should be taken in written form and should be duly documented in Parent Council Register." ${ }^{9}$ This indicates that, on paper at least, PEF does encourage parent-teacher councils; however, no such councils or registers existed in any of the schools visited in the sample. Moreover, about 90 percent of school owners and teachers complained about the lack of parental participation in PEF schools and highlighted this as a challenge. One principal said: "Parental participation is very low. Parents don't even come to the meetings we arrange for them. This is a big problem for us. We call and check when kids are absent. I also contact parents if the child is not doing well and is not preparing well for the test. But we don't get a good response on that and they say that it's the school's responsibility to educate their child." 60

Another principal reported: "There is no choice for students and their parents in this context. Sometimes it's the only school they can send their child to. There is no competition for EVS owners; they know that parents will send their kids here, so why work extra. There is no competition in terms of quality and learning. PEF school owners are only concerned about the QAT... Parents have no sense or understanding here about the providers in education and the differences between them. Parents have no aims, no thinking on which grade we will educate them to; they are not engaged in this. No SMCs exist in PEF schools, and parental participation is very low. In fact, I think in schools where parents pay a fee they are more involved and they come to inquire about their child." ${ }^{1}$

Teachers in focus group discussions also raised this as a challenge. A teacher from a PEF school in Rajanpur, a very underprivileged region of South Punjab, stated: "Parents are not concerned about the quality of education as they themselves are not educated. There are no SMCs in our schools. Parents do not even come when we write to them or call them. They cannot differentiate between quality of education in government, PEF, and private schools. It's not like they can make a choice. We cannot give students uniform or ghee (butter) to parents like some government schools in the area which do so to boost enrollment. Then parents often move their kids to these schools or threaten to move them to schools where they are offered something." 62

These testimonies highlight the absence of SMCs and the low level of parental participation in PEF schools, and they also raise questions about parental choice in private and PPP schools. A key argument put forward by the World Bank and PEF is that PEF schools run by private partners provide 
greater choice to parents. However, principals and teachers in the PEF schools in the sample did not believe that parents were able to exercise any meaningful choice as to which schools their children attended, and also that parents were unable to differentiate between different providers of education in terms of quality. This corroborates findings by Car-Hill and Murtaza (2013) and a third-party evaluation report of PEF schools which highlighted that while in theory "freedom of choice" should mean that PEF schools are more accountable to parents, no evidence was found that parents were getting involved in school governance or that they had chosen a school because it was presumed to offer better-quality education (IDS, 2008, p.49). The findings of this study corroborate this for schools in all four PEF programs. Whatever the reasons for the lack of parental participation and engagement in the mechanisms of "choice," it suggests that arguments about choice are very weak and that parents and community members are not involved in PEF schools. The element of choice and increased parental engagement in schooling both seem to be missing in this context.

\title{
Challenges and issues in monitoring of schools
}

\author{
"PEF examiners are rude to both students and teachers and create an environment of fear as \\ soon as they enter. They threaten students before the exam. The PEF monitors are not \\ qualified and don't have a sense of how to deal with children and teachers. They are always \\ looking for excuses to penalize schools and school owners. They often visit the school after \\ working hours. They arrive 15 minutes before we close. Then we have to keep kids in school for \\ hours afterwards. Sometimes students have already left and then they say that your enrollment \\ and attendance are not complete." (Teacher, focus group discussion 1)
}

Ninety percent of the school owners, principals, and teachers who took part in this study reported that they faced challenges in their work on account of PEF's monitoring of their schools. Both principals and teachers reported that PEF monitors (inspectors) were rude to them, visited schools near the end of the day or at times when enrollment would be low, and found excuses to penalize and humiliate principals and teachers. One principal summarized the general feeling of frustration: "Many PEF monitors are corrupt and unfair and no one is there to check them. They come and put penalties on low enrollment or anything to do with the building. Many of them pocket this money; no one is checking them for the money they make when they penalize schools. PEF only pays the per-child amount and it cuts even that through these penalties. There are no written rules about what they can penalize schools on. You only know about it when they fine you and deduct it from your payment." 63

A significant number of principals and teachers mentioned instances of similar corrupt monitoring practices by PEF monitors that they had witnessed themselves or heard about from other owners. They also noted that inaccurate monitoring practices included recording fake enrollments, despite PEF having a Student Information System database. While these reports could not be confirmed, they suggest that, while PEF tries to oversee private schools through monitoring, it may be doing so in a biased manner, which ends up creating distrust among private providers. The manner of inspection hampers the work of principals and teachers and has an effect on children, who suffer if they have to deal with a rude monitor. It also has a negative effect on the partnership model, as owners and teachers in PEF schools do not feel facilitated in their work. The concerns expressed about the monitoring of PEF schools are a serious issue that needs to be investigated further, as they call into question the transparency and accuracy of PEF's programs and monitoring.

\section{The myth of partnership}

"PEF does not support the school like a partner does. It's not a partnership. They need to understand issues and help us to rectify them before cancelling a school [from the program]. We have genuine issues here in this area and we are dealing with a tough student population. Teachers are not facilitated or trained, nor is there any cooperation from parents. PEF is not concerned about actually facilitating a partner school or helping them to provide a quality education." (Interview with principal, School No. 3) 
An astounding 97 percent of school owners, as well as teachers and CSO officials interviewed, complained that they did not feel that they were partners with PEF and that their relationship was more one of answering to an authority.

PEF is not based on a cooperative model but is essentially a regulatory model, where PEF is trying to control private school owners through reward and (more often) punishment. The notion of partnership is stretched to allow for this kind of relationship. In essence, PEF is buying a service from the private sector, while also setting the rules and conditions for the payment. There is a lack of trust between the two sides, which contrasts sharply with the model of partnership.

\section{Political affiliations and administrative irregularities}

Both school owners and other stakeholders reported that they believe political affiliations are important when PEF selects its school locations and partners. Some owners alleged that, increasingly, schools are being allotted based on individuals' political affiliations to the province's ruling party. One owner said: "There are many instances of school owners in PEF who've used different channels to get schools and to get their friends and relatives funding for running a school with PEF support." 64

Interviewees were also vocal in expressing concerns about instances of corruption and bribery practices among PEF monitors, for example accepting payments in exchange for a good school report or higher enrollment numbers. While the allegations of corruption among PEF monitors could not be verified, the reports bear out some of the arguments made by Car-Hill and Murtaza (2013), who identified possibilities of corruption based on an analysis of the activities and processes involved in PEF's Education Voucher Scheme. These authors argued that there was a high risk of very poor and vulnerable children being excluded because of the way in which areas are selected, fake enrollments in PEF schools, poor attendance rates due to a lack of parental motivation, the charging of fees for absent students, and poor educational outcomes because of poor-quality teaching. There is also a concern that the (semi-) public agency responsible for designing and allocating the PPP contract is also monitoring it. Galetovic et al. (2009, p.16) call this "bad governance" because it can lead to conflicts of interests (for instance, in the bidding process) as well as inefficient selection of projects and schools.

School owners and stakeholders also claimed that numbers in PEF's monitoring and reports were often inaccurate. One principal said: "Many owners benefit from PEF. They upload data that is inaccurate. I just couldn't lie or get parents' documents made through unfair means like other school owners, so we suffered." 65

Another claimed: "Despite all the systems they have put in place for attendance, etc., there are still serious issues of inaccuracy in PEF enrollment numbers. School owners do not report the kids who have dropped out, and they continue to have them in the system and keep getting funding for them. Once when PEF officials came to give out vouchers, they called out a child's name, but he wasn't there, so the PEF official waved to me and said: 'It's OK, let it go, we have given you that child's voucher.' When I said the child was not there, he asked me: 'Don't you need the money? Don't you need the voucher?' So that shows you that there are discrepancies. If you went to check the enrollments of PEF students you would find that many are not actually there in schools, and the numbers are not correct. Now in NSP and FAS schools monitoring is very light, perhaps once in six months, and in that case, there is more chance of fake enrollments. EVS schools are monitored more often. They distinguish between their different programs." 66

While these accounts are insufficient to provide a finding on the prevalence of corruption, they point to a critical concern about the reliability of data. The World Bank, bilateral donors, and local policy makers all rely on data supplied by PEF on its own schools, consisting primarily of enrollment numbers and test scores. These data are used to show the gains made through PEF programs and to demonstrate that they are successful. However, it is very concerning that partner schools, which provide the data that PEF then verifies, are raising concerns about the accuracy of numbers presented by PEF. Government education systems, including in Pakistan, are often accused of being inefficient 
because of corruption at various levels, and PPPs are often justified as a more efficient and less corrupt alternative. If PEF is associated with similar practices by its partners in the private sector, then one wonders how different and efficient it is compared with the public education system. This question was also raised by various stakeholders whose views are presented in the following section, which looks at PEF and PPPs in the wider context of the education system in Punjab.

\section{WIDER SYSTEMIC ISSUES}

This section draws on interviews conducted with various stakeholders, who provided information about the wider system of education in Pakistan in general and in Punjab specifically and gave their views on how the PPP conducted through PEF is responding to some of the challenges in education. Interviewees were vocal about issues of sustainability, access, equity, quality, and accountability, as well as PEF's functioning as an organization. They also reflected on the impacts that these issues had on the public system of education.

\section{Education as a business in Pakistan}

Interviews with stakeholders indicated that PPPS, and PEF itself, are based on an acceptance of the fact that education is increasingly privatized in the Pakistani context. This point provides insight into the context in which the PEF program is considered to be thriving and expanding at a rapid pace. Many stakeholders further indicated that a primary motivation for private owners to run schools is for business reasons.

A CSO official interviewed for the study said: "PPPs in Pakistan are not properly planned. PEF schools are working for business and political gains, but not for educating children. They are not catering to poor or out-of-school children. Education is now a business. They say that teachers are present in class, so there is some kind of education taking place, but quality is not a concern. Their motives are different." A consultant/researcher said: "Education is the best business in Pakistan. Schools multiply like anything. Starting with one school, people expand to 10 schools. Businessmen are now turning to it, as it offers minimum risk and maximum profit. There are no regulations. PEF schools are now schools for money."

In promoting the PPP model in Pakistan, both donors and the local government have argued that the private sector is considered to be more efficient and can help the government address its education crisis. An interview with a donor official in Islamabad emphasized this point: "I believe there is a lot of energy and competency in the private sector that the public sector can tap. A lot of people come to Lahore to observe PEF and try to replicate it. It's a very superior product line and very superior way of managing partners... If you enforce a minimum wage in this LFPS sector, the sector would collapseit won't work. That's the business model: most schools cannot enforce a minimum wage, otherwise the school would close; that's the nature of the economy."

This description of PEF's programs as a "superior product line" is an interesting illustration of the market-based rhetoric used by some donors when talking about PEF and its success as a case of educational reform. However, it is also alarming, as it reveals that some donors are aware that the labor rights of female teachers are being violated in this model. Sacrificing labor rights should not be considered an efficiency gain; this suggests that the whole model is based on the exploitation of poorly paid teachers, who are readily available in the labor market.

\section{PPPs: Donor-driven but locally owned?}

"PPP is like a buzzword, fancy terminology; we use it because donors use it and like it. After a decade another term, another policy will come and we will catch on to that." (Interview with a donor official, Islamabad) 
The interviews with stakeholders raised some important points about the role of donors as well as local government in pushing for PPPs in Punjab. In an interview, a World Bank official acknowledged that PPPs were being driven by key donors, including DFID, and have also been embraced by the provincial government, which is now aiming to transfer a large number of public schools to the private sector, with the aim of showing educational progress to voters.

The World Bank official explained: "The commitment to implement PPPs and engage the private sector is definitely there by the government in Punjab. Around 4,500 public schools have already been handed over to private partners to run in the PSSP program. Their goal is to increase the number of these schools to 10,000 , which is a fifth of the education system. I do feel that it is more of a quick-fix approach sometimes and the sense of ownership is missing in the projects, but politically they are driven to show improvement in education and PPPs are there for that."

The view that the Punjab PPP is a donor-driven policy was held by other stakeholders. A CSO official stated: "I think these initiatives are largely due to donor push and interest in funding a PPP project in the provincial education system. So if the Punjab government wants to get these funds, it has to act accordingly and embrace PPPs, and also show that it owns them. Why did PEF restructure in 2004 and all of a sudden become actively involved in programming for PPPs? The World Bank was behind the funding and the enthusiasm in that period."

Another donor official said: "Certainly we can improve the government system of education. But PEF is good money. The World Bank and DFID are major donors. So it's a donor-driven program. The idea comes from the US and the UK. They call them chartered [sic] schools and academies and we call them private. Now you need to understand that the donor is important here. The donor doesn't want this to go to the government, so that is a driving force too. The reality is that it's a conditional grant for budgetary support, and one of the conditions is that it will go to fund PEF and the private sector. That defines the parameters of funding at the provincial level."

These views give some insight into the political economy of educational reform in Pakistan. While the government's own perspective is lacking in this study, some key stakeholders feel that donor discourse on PPPs is adopted and embraced by local government in furtherance of its own goals of obtaining funding and showing its drive for improvement to voters, and see PPPs as an imported concept, based on models of vouchers and charter schools in donor countries.

\title{
Sustainability of PPPs and PEF programs
}

\begin{abstract}
"Punjab is the graveyard of reforms in the education sector. You think of a reform and we have done it, but we have not seen any results either in children's learning or in increased access for the marginalized. One of the reasons for the lack of results is that we do not have feedback loops that over time make these policies better. A lot of literature says that it is not a good idea to raise the stakes for teachers in that sense. There is a lot of reflection that should go into policy-making, and I find that in education we do not have that on the government side. PEF suffers from the same problem: basing everything on the QAT means that the whole structure has become wonky." (Interview, official from a research organization)
\end{abstract}

The sustainability of donor-funded programs is key, especially in a sector like education, where it takes years to demonstrate results and improvement. However, many education policies in Pakistan fail due to the lack of a long-term vision and planning behind them. Stakeholders interviewed for this study were asked about their views on sustainability. Interestingly, the interview with the World Bank official showed that even Bank staff are concerned about the sustainability of reforms in Punjab at the moment: "We don't know what the exit strategy is here and the question of sustainability remains. The answer of sustainability needs to be given by the government. ... [There is a feeling] that the rate at which they are expanding is not sustainable... [They] think of the short term but not longer-term plans. PEF's own expansion programs are very ambitious." Another donor official interviewed raised similar concerns and noted that "the Bank has given a loan, so the country and our generations will continue paying for it. There is a big sustainability question." 
However, a DFID official had a different view: "Look, once a policy becomes successful it becomes very difficult to phase out from that, because suddenly you would have 200,000 children without services. The government wouldn't want this headline in the newspaper... So I don't think it's an issue. Several DFID programs in Punjab have been sustained. Of course PEF won't have all the boxes ticked on future strategy now, but they will develop it over time. During the next two years I don't think it will be discontinued, but I agree that more work needs to be done to have its sustainability figured out."

These perspectives of staff from various donors seem to suggest that there are mixed views among donors themselves about the longer-term sustainability of PEF's programs and of educational reform in Punjab. Given the temporary nature of World Bank loans and bilateral donor support, and the sometimes short-term focus of government, it seems that the sustainability of PEF's programs is a significant question requiring more attention. Despite the rhetoric trumpeting the success of PEF programs and their rapid expansion, some stakeholders are skeptical about their long-term future and are concerned about the lack of planning for the role of PPPs in the education system.

\section{Impacts on the public school system}

One limitation of this study is that it was unable to include perspectives from representatives of the public, government-run school system in Punjab in order to better understand how PPP schools are affecting them and their work. However, the stakeholders who were interviewed provided some valuable insights into the system of education in the province as a whole and how the increase in support for PPPs and PEF might affect its public schools.

The World Bank official, for instance, said: "There is no trade-off, as we see it as complementary; we support both public and private. You see, we believe that the public education system doesn't have the capacity to cater to all the kids in the province, so we need to bring in the private sector, and if you look at enrollment it is quite satisfactory as a program." Meanwhile the DFID official stated: "I think PEF will become so big and it will create so much momentum that it will pressurize government schools to do better. They will have a fear of being outsourced."

However, in contrast to these donor perspectives, other stakeholders interviewed felt that the support given to PEF was weakening the public education system, which is already struggling. A consultant/researcher with a CSO said: "Money should not be given to PEF for funding private schools but should be spent on public schools to improve their facilities and to make governance of the schools more accountable. The issue is that we need to reform the public system of education in Pakistan. Funding the private sector through PPPs is a wrong step. Instead of strengthening your government institutions, you are weakening them. And another thing, the Punjab government has given thousands of schools to PEF, and PEF has distributed those schools to individuals and NGOs. It means that the provincial government is not sincere in becoming the custodian of education and ensuring the right to education for every child. If public schools are lost, it's concerning and damaging for the education system."

An official from a research think-tank said: "The fact remains that we know from the results of the Punjab Examination Commission and other exams that actually children in both of these types of schools are failing and on average are doing very badly. Children in private schools are doing slightly better, but only in comparative terms. It is like saying that somebody is getting 15 percent and someone is getting 22 percent: both are failing very badly, though one is better than the other. What is not being looked at is the issue of private tuition. There is plenty of evidence that private tuition is massively widespread, and much more so in private schools than in state schools, so how do you account for a factor like that? What you need to do is to work on the public schools to provide a benchmark, a minimum quality. If you improve the quality in public schools, then the private schools have to pitch themselves higher. By definition, they will improve quality through competition, instead of the current argument that private will improve public. That is not happening in Pakistan." 
The civil society stakeholders raise a number of concerns. Firstly, it is argued that the government has a large system of public education, but with increasing amounts of financial support going to PEF schools, less funding is available for public schools. Secondly, the quality of education is generally poor in both public and private schools (as borne out by the academic literature discussed previously). In contrast to the argument made by donors, these stakeholders believe that quality across Punjab's education system can only improve if public schools start providing a higher quality of education.

\title{
Risk of entrenching inequality and social stratification
}

\author{
"They say that Pakistan is not a poor country, it's a poorly governed country. We have the \\ resources. The government's education sector is huge, and it has the manpower of six million \\ people. But the question is, have we created a parallel structure by bringing in PPPs and the \\ private sector? Is it sustainable? Why have we created a different system-why don't we fund \\ the public sector? There is a serious issue of political will here. In Pakistan, it's missing." \\ (Interview with a donor official)
}

In their interviews, stakeholders pointed out that the advent of PPPs in Punjab has created a parallel education system to that run by the government. Increasingly, they are questioning the rationale of this parallel system and the prospect of the province attaining the goal of education for all. A CSO official stated: "PEF is not working towards Education for All [EFA]. They claim that they are, but it's not really the case. Look at the current status of education in Punjab, look at the low learning levels and high dropout rates: it's definitely not education and learning for all, gender has not improved. Girls are still doing less well than boys. The PPP is not addressing gender, not catering to out-of-school children, and not including children with disabilities, so how can it be working for EFA?"

Another official with a CSO said: "I don't really buy the argument about government failure leading to the opening up of private schools. The causality is not clear to me at all. I think that the middle and higher classes have withdrawn from public spaces and have created these enclaves for themselves. It's cheaper to do this. It entrenches inequality even more, it's class interest, whatever you want to call it. It is an endogenous process that is linked, so it didn't happen that state schools failed and then we brought in private. The private sector depends on the ability to pay, and that for most of Pakistan is very problematic. So I think it's an excellent way of entrenching the rule of the country's elite class."

An official from a research organization said: "I don't see these aspirations of PPPs as anything more than rhetoric, [about] the SDGs and [Article] 25A. But there is never really any intention to make it happen, otherwise your actions would speak for the change as well. This entire thing about having given up on providing education to everybody and allowing the private sector to come in without any regulation and wreak complete havoc on any notion of equity, of equality, of any semblance of an idea of a similar education for children from all walks of life-we have just given up on that. If a system has a low-cost fee-paying school and a system that allows for a fee of PKR 50,000 [\$430] per month, how can you have any notion of equity running through that system? The quality of education at the lower end is very poor. We have given up on the dream of equity and equality; maybe we never had them, but clearly they are not operational now."

Many stakeholders interviewed felt that PEF programs are not eliminating inequality and inequity from Punjab's education system. This echoes an observation from an earlier study that subsidizing private schools in Pakistan may build the capacity of school owners but not that of the education system to deliver in the long run, and that this is not sustainable (Malik and Rose, 2015). Moreover, by catering to students selectively, the PPP may be worsening the situation by further encouraging a stratified, segmented education system and potentially deepening economic inequalities.

The findings from this study's fieldwork suggest that PEF schools are not targeting children who are marginalized due to poverty, gender, or ability. When asked about this issue, the World Bank official admitted: "We don't really know if PEF is contributing to getting out-of-school children into school. We don't have the data on out-of-school children, and determining their numbers is very tough. I think the 
NSP program where they fund private schools in areas where there were no schools before, perhaps makes the argument that it's for out-of-school children, but there's no verification of that I think."

This suggests that there is a need for the World Bank and other donors to help the government develop a better system to collect data and evaluate its programs with regards to the background and demographics of students who are accessing schools, including socio-economic class, gender and disability. Moreover, the stated objective of PEF's programs is to cater for children who are marginalized, including those who are out of school and girls. Since PEF is unlikely to be reaching these children, there are important questions to be asked regarding its usefulness as an education reform policy. 


\section{DISCUSSION OF KEY FINDINGS}

"The biggest question that models of PPPs with LFPSs generate concerns the extent to which the governments of low-income countries will have the capacity to enforce and enact the necessary regulations and accountability mechanisms to ensure that [these types] of private schools respect public education principles and, accordingly, do not discriminate against the most disadvantaged students with their school admission procedures or expulsion policy, or do not charge uncovered fees that the poorest families cannot afford to pay." (Verger, Fontdevila, and Zancajo, 2018, p.269)

\section{EQUITY}

Considering the findings of this report on access to education, it seems unlikely that the World Bank's goal in PESP of bringing "1 million out-of-school children to school in Punjab" will be achieved through PEF's programs (World Bank, 2016, p.7). This report's findings suggest that the number of out-ofschool children in PEF schools is likely to be very low and dropout rates for these children very high. This is particularly concerning as Punjab accounts for more than 45 percent $(11,415,282)$ of Pakistan's out-of-school population of 24 million children (Alif Ailaan, 2015).

While gender is considered a cross-cutting theme in PESP, insights from the field show that PEF schools are not paying "special attention to gender dimensions to improve participation, completion, and quality of teaching-learning practices for female students and teachers" (World Bank, 2016, p.20). Evidence on the enrollment of girls in co-educational PEF schools included in this study indicates that girls are still fewer in number than boys, and participants argue that much needs to be done to increase girls' enrollment and, more importantly, their retention rates after Grade 5. PEF does not have a quota for female students in any of its schools. Because of their gender and a culture that favors boys in acquiring education and employment, girls are more likely to be excluded from PPP schools and are doubly discriminated against if they have a disability or belong to a poor household that cannot meet non-fee expenditures. Dropout rates for girls are also high in PPP schools due to factors including early marriage, the unpaid burden of care work, and girls' limited mobility, especially in rural and slum localities. In Pakistan, where more girls are out of school than boys (12.8 million girls compared with 11.2 million boys (Alif Ailaan, 2015)) and girls are less likely to complete their schooling, gender needs to be the key focus of any educational reform.

Gender discrimination in education is also apparent in employment, with schools in the LFPS sector employing a largely female teaching workforce. The treatment of female teachers in LFPS and PPP schools, who are paid very low salaries far below the minimum wage, is a violation of their labor rights. This, combined with the pressure of high-stakes testing for the QAT in PEF schools and a lack of training opportunities, means that female teachers in PEF schools are disempowered. This corroborates earlier findings that LFPS are dependent on poorly paid, disempowered female teachers, thus entrenching gender inequality in the education system and the labor market.

The findings also suggest that PPP schools in Punjab are unable to accommodate students with disabilities, despite the Punjab government's recent interest in inclusive education. In addition, children from extremely poor backgrounds still cannot afford the costs of attending PPP schools: much of the increase in educational access for poor families has been negated by the non-tuition fee expenditures in PPP schools for uniforms, transport, and other costs. The findings of this study highlight the intersections between gender, poverty, and disability and the failure of PEF to really grapple with the underlying issues of poverty that cause children to be excluded and to perform poorly in schools. 


\section{QUALITY}

The findings of this study suggest that the World Bank's strategic objective of "ensuring quality teaching and learning for all" is not being met by PEF's programs. PEF's use of a "reward and sanction" model that views the QAT as the sole criterion of quality appears to be creating perverse incentives that result in exclusion rather than providing support to teachers and schools to enhance learning, along with the tools and resources they need. In its Project Appraisal Document for PESP III, the Bank acknowledges that "the quality of the QAT test content and administration has not been reviewed in years" (World Bank, 2016, p.4), but PEF, along with the Bank and bilateral donors, continues to rely on the results of the poorly designed QAT as an indicator of quality. Teaching to the test and rote memorization are prevalent in PEF schools. A majority of the school owners, trainers, and other stakeholders who participated in the study argued that PEF schools are not providing quality education. Moreover, the incentives tied to performance in the QAT have become incentives for selection or exclusion, as schools are skimming off high-performing students for enrollment in their schools. Those who cannot afford private tuition, children with a disability, and children who are out of school are generally those who are very weak academically and so are unable to pass the screening tests of PEF schools and end up being excluded. The findings of the study call into question the whole idea of incentives to improve learning and suggest that this model is at odds with the right to education.

The study also seriously calls into question the claim that PPP schools are more cost-effective and provide better value for money. Principals and teachers participating in this study asserted that the amount being paid per child by PEF was inadequate for them to ensure that the school had suitable physical infrastructure, teaching materials, and qualified and trained teachers. The study shows that these cost savings come with a high price, and that schools are sacrificing quality due to a lack of investment.

The findings also show that a lack of regular teacher training programs, a high turnover rate of teachers, and the inability of schools to strengthen and facilitate the work of teachers are factors that are negatively affecting the quality of education in PPP schools in Punjab. Many threats to equity are equally threats to the quality of education: for example, the lack of safe and child-friendly learning spaces affects children and their educational attainment in unequal ways (Oostrum, 2013, p.50). The Incheon Declaration states that committing to quality requires ensuring "that teachers and educators are empowered, adequately recruited, well-trained, professionally qualified, motivated and supported within well-resourced, efficient and effectively governed systems" (UNESCO, 2015, p.8,). As highlighted by UNESCO, "It is neither possible nor acceptable to demand that teachers respect children's rights when their own rights are violated and ignored. Ultimately, unless the rights of teachers are respected, a quality education for children cannot be achieved" (UNESCO, 2017, p.72).

\section{ACCOUNTABILITY}

"Large-scale PPP arrangements are not only more risky for the public sector, as there are fewer actors to bear the risk, but also... operate with vested interests against those of the public, [which] can lead to more complicated regulatory frameworks not less, and... have the potential of becoming 'abusive' if the stronger partner dominates." (Srivastava, 2014, p.2)

"In their eagerness to treat private schools as a sustainable model of education service delivery, donors are potentially overlooking concerns of equity, quality gaps in low fee private schools themselves, and the inability of the provincial governments to regulate these schools." (Malik and Rose, 2015, p.19)

While World Bank documents on PESP note support for the creation of school councils in the education system more broadly (World Bank, 2012a), this study suggests that school councils are not functioning on the ground in PEF schools, and in many cases have never existed. Moreover, the 
school owners, teachers, and other stakeholders interviewed for this study complained of a lack of parental participation in their schools. PEF officials do not interact with parents and are not concerned with parental engagement in children's progress, the quality of teaching, or school facilities. School owners in the EVS program send nominations to PEF and essentially have the power to decide which children can apply for a voucher. The whole idea of participation and choice for parents is missing in this program and in LFPS, as the testimonies of participants demonstrate. These findings call into question the argument that private schools are more accountable to parents and the communities in which they operate. The study also calls into question accountability as a whole in PPP schools. This broader accountability is at odds with test-based accountability centered on the QAT (which the study finds does not really work) and democratic or social accountability to communities (which it finds is not present in PEF schools). Moreover, PEF's reluctance to facilitate access to its schools for research purposes suggests a lack of transparency and openness to scrutiny.

The findings also show that the wider systemic issues of inequity, inefficiency, corruption, and low quality of education that plague the public system of education in Punjab are also apparent in PEF's programs. The UN Committee on Economic, Social and Cultural Rights (CECSR) has raised concerns about the increased number of LFPS being established under the banner of PPP initiatives, finding that there is a lack of effective regulation of such schools, which are of poor quality and charge high non-fee expenses. ${ }^{67}$ The CECSR, in common with many of the stakeholders who participated in this research, notes that this has reinforced social segregation in education in Pakistan, with the wealthy sending their children to elite private schools while children from working class and poor backgrounds attend underfunded public schools or PPP schools. The findings of this study bear out these observations and indicate the failure of PEF's programs to engage with the underlying issues of poverty and economic and gender inequality in Punjab that are contributing to low performance among poorer and more marginalized groups. PPP schools are part of a "quick fix" approach, rather than tackling the root causes of exclusion and low quality in the provincial education system, and therefore they are unlikely to be a meaningful or sustainable reform in the long term. This study also raises concerns about the way that public education is being neglected and underfunded in favour of PPPS. This is highlighted by the ASER 2016 report (p.17), which points out that the poorest quartile of Pakistan's population has the highest proportion of children enrolled in government schools (77 percent). 


\section{CONCLUSION}

Article 25A of Pakistan's constitution guarantees the right to education, but with a large population of out-of-school children and rapid privatization in the education sector, it is crucial to investigate reforms such as those undertaken in Punjab to analyze what impact they are having on the right of all children to a quality education. It is hoped that this research will contribute to enhancing understanding about the PPP programs in Punjab, highlighting the important issues of inequitable access for children from marginalized populations, the low quality of educational provision, the lack of parental participation, and weak accountability in PEF schools.

The research suggests that the design of Punjab's PPP is flawed, as it is based on an ineffective system of incentives for private sector providers that is resulting in low-quality education and the exclusion of marginalized children. Using the QAT as the sole criterion for judging school performance is problematic. Findings suggest that non-fee expenditure in PEF schools and the preference of school owners to take students who can perform well in testing result in the exclusion of children from very poor backgrounds, especially out-of-school children. They also suggest there are no places reserved for girls and no accommodation for children with disabilities in PEF schools. Teachers, who are primarily female and on average have only a Grade 12 qualification themselves, are paid very low salaries, substantially below the minimum wage. The lack of training in PPP schools and the pressure of the high-stakes QAT combine to create a disempowering working environment for female teachers. It is therefore concerning that in the current system of PPP schools it seems the rights of both students and teachers are at risk of being violated. Furthermore, school owners, teachers, and other stakeholders all highlight the lack of reliable data on PPP schools, and raise concerns about possible corrupt practices, especially in monitoring activities.

The findings presented in this report substantiate the argument that increased privatization of education risks contributing to greater economic and gender inequalities by creating inequitable access to education and inequitable outcomes, and thereby potentially increasing socio-economic segregation and stratification.

Both the results and limitations of this study indicate opportunities for future research. Reflecting on the limitations of a relatively small study, similar research should be carried out in Punjab and other contexts such as Sindh province, where a similar program is underway, to build the evidence base on PPPs in education. Other key stakeholders such as parents and community members need to be included to obtain deeper insights into accountability and citizens' participation in LFPS.

It is hoped that donors, including the World Bank, and local policy-makers and influential leaders in Punjab and Pakistan more widely will reflect and take meaningful action on the findings, key messages, and lessons of this study in order to more effectively fulfill their obligations to provide equitable access to quality education for all Pakistani children.

Moreover, the findings of this study should lead the various actors involved to rethink PPPs in the context of Pakistan and develop educational reforms that are sustainable in a country that is known for its failed reforms and donor-driven plans for education. The public education system cannot and should not be ignored. However, local and global actors are shaping public education reform and policy in Pakistan that is often based on flawed assumptions, as opposed to strong evidence on the role of the private sector. The current PPP in Punjab is also a case of how faulty incentives and the implementation of programs that support private schools can potentially risk damaging an already weak system of public education. Attention must be refocused on providing quality education to all the children in Pakistan and fulfilling the rights enshrined in Article 25A of the constitution, rather than on PPP programs that may lead to the deepening of an unequal, inequitable, and stratified system of education. 


\section{BIBLIOGRAPHY}

Afridi, M. (2017). Understanding the work of female teachers in Low Fee Private Schools in Punjab, Pakistan. Unpublished doctoral dissertation. OISE: University of Toronto.

Alcott, B. and P. Rose (2015). Schools and learning in rural India and Pakistan: who goes where, and how much are they learning? University of Cambridge: UK.

https://www.repository.cam.ac.uk/bitstream/handle/1810/247631/Alcott and Rose 2015

Prospects.pdf?sequence $=1$

Alif Ailaan and SDPI (2016). Pakistan District Education Rankings 2016. Islamabad: Alif Ailaan. https://d3n8a8pro7vhmx.cloudfront.net/alifailaan/pages/537/attachments/original/1474368820/Pakista n District Education Rankings 2016 Full Report.pdf?1474368820

Alif Ailaan (2016). Pakistan Education Statistics 2014-15.

https://d3n8a8pro7vhmx.cloudfront.net/alifailaan/pages/496/attachments/original/1473162927/The St ate of Education in Pakistan.pdf?1473162927

Alif Ailaan (2014). The voice of teachers: learning from teachers across Pakistan. Islamabad: Alif Ailaan. https://www.alifailaan.pk/voice of teachers

Alif Ailaan (2015). Not free at all: profiling the costs parents incur on education. Islamabad: Alif Ailaan. https://www.alifailaan.pk/notfreeatall

Alegre, M. À. and Ferrer, G. 2010. School regimes and education equity: some insights based on PISA 2006. British Educational Research Journal, Vol. 36, No. 3, pp. 433-461.

https://doi.org/10.1080/01411920902989193

Alves, F., G. Elacqua, M. Koslinki, M. Martinez, H. Santos, and D. Urbina (2015). Winners and losers of school choice: Evidence from Rio de Janeiro, Brazil and Santiago, Chile. International Journal of Educational Development, Vol. 41, pp.25-34. https://doi.org/10.1016/j.jjedudev.2014.12.004

Amjad, R. and G. Macleod (2012). Exploring aspects of private, public and private-public partnership (PPP) schooling in Pakistan. Paper presented at the Globalization, Regionalization and Privatization in and of Education in Asia Conference, September 28-29, 2012, Kathmandu, Nepal. Open Society Foundation/Privatization in Education Research Initiative.

Andrabi, T., J. Das, A.I. Khwaja, S. Ozyurt, and N. Singh (2015). Upping the Ante: The Equilibrium Effects of Unconditional Grants to Private Schools.

https://khwaja.scholar.harvard.edu/files/asimkhwaja/files/20180617 grants.pdf

Andrabi, T., J. Das, and A.I. Khawaja (2011). Students Today, Teachers Tomorrow? Identifying Constraints on the Provision of Education. Policy Research Working Paper, World Bank: Washington, D.C. https://openknowledge.worldbank.org/bitstream/handle/10986/3437/WPS

5674.pdf?sequence $=1 \& i s$ Allowed $=y$

https://doi.org/10.1596/1813-9450-5674

Andrabi, T., J. Das and A.I. Khawaja (2008). A Dime a Day: The Possibilities and Limits of Private Schooling in Pakistan. Comparative Education Review, Vol.52 (3): 329-355.

https://doi.org/10.1086/588796

Andrabi, T., J. Das, A.I. Khwaja, T. Vishwanath, T. Zajonc, and the LEAPS Team. (2008). Pakistan: Learning and Educational Achievements in Punjab Schools (LEAPS): Insights to Inform the Education Policy Debate. Islamabad: World Bank.

http://documents.worldbank.org/curated/en/997531468090281061/Pakistan-Learning-and-

Educational-Achievements-in-Punjab-Schools-LEAPS-insights-to-inform-the-education-policy-debate

Annual Status of Education Report (ASER) (2016). http://aserpakistan.org/report

Annual Status of Education Report (ASER) (2012). Lahore, Pakistan. Facilitated by South Asian

Foundation for Educational Development.

http://aserpakistan.org/document/aser/2012/reports/national/National2012.pdf 
Ashley, L.D., C. Mcloughlin, M. Aslam, J. Engel, J. Wales, S. Rawal, and P. Rose (2014). The role and impact of private schools in developing countries: A rigorous review of the evidence. Final report. EPPI-Centre Education Rigorous Literature Review Reference Number 2206. London: DFID.

Aslam, M., B. Jamil, and S. Rawal (2011). Teachers and School Quality: Some policy pointers from Rural Punjab. Lahore: SAFED.

http://aserpakistan.org/document/aser policy briefs/2011/Policy Brief Teachers and School Quality .pdf

Aslam, M., S. Rawal, and S. Saeed. (2017). Public-Private Partnerships in Education in Developing Countries: A Rigorous Review of the Evidence. Ark Education Partnerships Group. http://arkonline.org/sites/default/files/ArkEPG PPP report.pdf

Bano, M. (2008). Public Private Partnerships as 'anchor' of educational reforms: lessons from Pakistan. Paper commissioned for the EFA Global Monitoring Report (2009): Overcoming Inequality: Why governance matters. http://unesdoc.unesco.org/images/0017/001780/178017e.pdf

Bari, F., M. Aslam, N. Maqsood, R. Raza, and B. Khan (2013). An Investigation into Teacher Recruitment and Retention in Punjab. IDEAS: Lahore, Pakistan.

http://ideaspak.org/images/Publications/Human-Development/Teacher-Recruitment-and-Retention.pdf

Barerra-Osorio, F. et al. (2015). Leveraging the private sector to improve primary school enrolment: Evidence from a randomised controlled trial in Pakistan. Mimeo.

https://www.riseprogramme.org/sites/www.riseprogramme.org/files/inline-files/Felipe\%20BarrraOsorio\%20pprs pakistan draft 20176 16.pdf

Barrera-Osorio, F., J. Guaqueta and H.A. Patrinos (2012). The role and impact of public private partnerships in education. In S. Robertson, K. Mundy, A. Verger, and F. Menashy (eds). Public Private Partnerships and Education: New Actors and Modes of Governance in a Globalising World. London: Edward Elgar. https://doi.org/10.4337/9780857930699.00019

Bau, N. and J. Das, (2017). The labour market for teachers in Pakistan: Pay and effectiveness. VoxDev. https://voxdev.org/topic/health-education/labour-market-teachers-pakistan-pay-andeffectiveness

Bellei, C. (2016). Dificultades y resistencias de una reforma para des-mercantilizar la educación. RASE: Revista de la Asociación de Sociología de la Educación, Vol. 9, No. 2, pp.232-247.

Bettinger, E.P. (2005). The effect of charter schools on charter students and public schools. Economics of Education Review, Vol. 24, No. 2, pp.133-147. https://doi.org/10.1016/j.econedurev.2004.04.009

Bifulco, R. and H.F. Ladd (2006). The Impacts of Charter Schools on Student Achievement: Evidence from North Carolina. Education Finance and Policy, MIT Press, Vol. 1, No. 1, pp.50-90. https://doi.org/10.1162/edfp.2006.1.1.50

British Council and Economist Intelligence Unit (2014). Moving from the margins: Mainstreaming persons with disabilities in Pakistan.

https://www.britishcouncil.pk/sites/default/files/moving from the margins final.pdf

Byun, S., K.-K. Kim, and H. Park (2012). School Choice and Educational Inequality in South Korea. Journal of School Choice, Vol. 6, No. 2, pp.158-183. https://doi.org/10.1080/15582159.2012.673854

Car-Hill, R. and A. Murtaza (2013). Assessing Possibilities of Corruption: The Example of the Punjab Education Foundation. UKFIET International Conference on Education and Development-Education \& Development Post 2015: Reflecting, Reviewing, Revisioning. Sub-theme: Futures of Development. Oxford, September 10-12, 2013. http://www.norrag.org/fileadmin/Events/Oxford/OxCon 2013 CarrHill Murtaza.pdf

Crawfurd, L (2018). Contracting out Schools at Scale: Evidence from Pakistan. Rise Working Paper, April 2018. https://www.riseprogramme.org/sites/www.riseprogramme.org/files/publications/RISE WP$\underline{022 \text { Crawfurd.pdf }}$ 
Cullen, J.B., B.A. Jacob, and S.D. Levitt (2005). The impact of school choice on student outcomes: an analysis of the Chicago Public Schools. Journal of Public Economics, Vol. 89, No. 5, pp.729-760. https://doi.org/10.1016/i.jpubeco.2004.05.001

Day Ashley, L., C. McLoughlin, M. Aslam, J. Engel, J. Wales, S. Rawal, R. Batley, G. Kingdon, S. Nicolai, and P. Rose (2014). The Role and Impact of Private Schools in Developing Countries. Education Rigorous Literature Review. DFID: London.

Di Gropello, E. (2006). A Comparative Analysis of School-Based Management in Central America. Washington D.C., World Bank Publications. https://doi.org/10.1596/978-0-8213-6525-0

DFID (2017). Punjab Education Support Program 2, Annual Review Report (4), August 2017. https://devtracker.dfid.gov.uk/projects/GB-1-202697/documents

Elacqua, G. (2012). The impact of school choice and public policy on segregation: Evidence from Chile. International Journal of Educational Development, Vol. 32, No. 3, pp.444-453.

https://doi.org/10.1016/j.ijedudev.2011.08.003

Galetovic, A., E. Engel, and R. Fischer (2009). Public-private partnerships: when and how. Stanford, CA: Stanford Center for International Development.

Gauri, V. (1998). School Choice in Chile: Two Decades of Educational Reform. Pittsburgh: University of Pittsburgh Press.

Gewirtz, S., Ball, S. J. and Bowe, R. 1995. Markets, Choice, and Equity in Education. London, Open University Press.

Government of Pakistan (2015). Household Integrated Economic Survey (HIES) (2013-14). Pakistan Bureau of Statistics: Islamabad. http://www.pbs.gov.pk/sites/default/files//ps/m/publications/hies2013 14/HIES 2013$14 \quad 18 \quad 03 \quad 2015 . \mathrm{pdf}$

Government of Pakistan (2014). Pakistan Social and Living Standards Measurement Survey (PSLM) 2012-13. Pakistan Bureau of Statistics, Islamabad.

Government of Pakistan (2003). National Plan of Action on Education for All Pakistan (2001-2015). Islamabad: Ministry of Education, in collaboration with UNESCO.

Hoxby, C.M. (2003). School choice and school competition: Evidence from the United States. Swedish Economic Policy Review, Vol. 10, pp.9-65.

Hsieh, C.T. and M. Urquiola (2006). The effects of generalized school choice on achievement and stratification: Evidence from Chile's voucher program. Journal of Public Economics, Vol. 90, 14771503. https://doi.org/10.1016/j.jpubeco.2005.11.002

ICAI (2012). Evaluation of DFID's Bilateral Aid to Pakistan. Independent Commission for Aid Impact. https://www.oecd.org/countries/pakistan/ICAl Pakistan Report P1.pdf

IDS (2008). Third Party Evaluation of Punjab Education Foundation Assisted Schools (PEF-FAS Program). Lahore: Innovative Development Strategies.

ILM IDEAS (2014). Access to Finance for Low Cost Private Schools. http://www.pmn.org.pk/assets/articles/583a24b1847ac755837917dba14fafd6.pdf

International Crisis Group (ICG) (2014). Education Reform in Pakistan. Asia Report No. 257 | 23, June 2014. Brussels.

Iossa, E. and D. Martimort (2015). The simple microeconomics of public-private partnerships. Journal of Public Economic Theory, Vol. 17, No. 1, pp.4-48. https://doi.org/10.1111/ipet.12114

I-SAPS (2016). Domestic Resource Mobilization in Pakistan: Exploring Avenues for Addressing Inequities. Institute of Social and Policy Sciences. http://i-

saps.org/upload/report publications/docs/1496384328.pdf

I-SAPS (2010). Private Sector Education in Pakistan: Mapping and Musing. Islamabad. 
Jabbar, H. (2016). Selling Schools: Marketing and Recruitment Strategies in New Orleans. Peabody Journal of Education, Vol. 91, No. 1, pp.4-23. https://doi.org/10.1080/0161956X.2016.1119554

Jennings, J.L. (2010). School Choice or Schools' Choice? Managing in an Era of Accountability. Sociology of Education, Vol. 83, No. 3, pp.227-247. https://doi.org/10.1177/0038040710375688

Khan, S.R. (2004). Pakistan under Musharraf (1999-2002): Economic Reform and Political Change. Lahore: Vanguard.

Kitaev, I. (1999). Private Education in Sub Saharan Africa: A re-examination of theories and concepts related to its development and finance. Paris: UNESCO.

LaRocque, N. (2008). Public-Private Partnerships in Basic Education: An International Review. CfBT Education Trust.

https://olc.worldbank.org/sites/default/files/CfBT LaRocque PPPs\%20in\%20Basic\%20Education\%20 An\%20International\%20Review 0.pdf

Lewin, K. (2013). Making Rights Realities: Does Privatizing Educational Services for the Poor Make Sense? Centre for International Education, University of Sussex. https://keithlewin.net/wpcontent/uploads/2015/07/Making-Rights-Realities-G20-PDFTEXT.pdf

Malik, R. and P. Rose (2015). Financing Education in Pakistan: Opportunities for Action. Country Case Study for the Oslo Summit on Education for Development, July 2015.

http://reliefweb.int/sites/reliefweb.int/files/resources/pakista.pdf

Malik R., F. Bari, I. Muzaffar, T. Mashhood, M. Mansoor, and A. Ali (2015). Partnerships for management in education: evidence from Punjab and Sindh. Institute of Development and Economic Alternatives.

Malik, A.B. (2010). Public-Private Partnerships in Education. Lessons learned from the Punjab Education Foundation. Mandaluyong City, Philippines: Asian Development Bank.

Malik, A.B (2007) Freedom of Choice: Affordable Quality Education in Public Private Partnership. Maqbool Academy Urdu Bazaar. Lahore, Pakistan.

Marshall, K. and A. Bauer (2000). The New Social Policy Agenda in Asia: Proceedings of the Manila Social Forum. Manila: Asian Development Bank and the World Bank.

McEwan, P.J. and M. Carnoy (2000). The effectiveness and efficiency of private schools in Chile's voucher system. Educational Evaluation and Policy Analysis, 22(3), 213.

https://doi.org/10.3102/01623737022003213

Menashy, F., K. Mundy, and M. Afridi (2014). The role of the World Bank in the private provision of education in Pakistan. In I. Macpherson, S. Robertson, and G. Walford (eds). Education, Privatisation and Social Justice: Case Studies from Africa, South Asia and South East Asia. Oxford: Symposium Books, pp.239-257.

Ministry of Education (2009). National Education Policy 2009. Islamabad: Ministry of Education, Government of Pakistan.

Ministry of Education (2004). Public private partnerships in the education sector: Education Sector Reforms Action Plan 2001-2005-Policy, options, incentive package and recommendations. Islamabad, Pakistan: MOE.

Mundy, K. and F. Menashy (2014). The World Bank and Private Provision of Schooling: A Look through the Lens of Sociological Theories of Organizational Hypocrisy. Comparative Education Review, Vol. 58, No. 3, pp. 401-427. https://doi.org/10.1086/676329

Oostrum, J (2013). Why measure access and quality of education through the use of the Capability approach? An exploration in the context of Nepal. Thesis for the M. Sc. programme on Development and International Relations (DIR) and European Studies (ES), Aalborg University.

Pakistan Economic Survey (2018). Pakistan Economic Survey 2017-18. Islamabad: Ministry of Finance, Government of Pakistan. http://www.finance.gov.pk/survey/chapters 18/10-Education.pdf 
Patrinos, H., F. Barrera-Osorio, and J. Guaqueta (2009). The Role and Impact of Public-Private Partnerships in Education. Washington, D.C.: World Bank. https://doi.org/10.1596/978-0-8213-7866-3

Pavon, F. Y. 2008. Improving Educational Quality in Honduras: Building a Demand-Driven Education Market. Journal of Public and International Affairs, Vol. 19, No. 1, pp. 194-213.

Punjab Education Foundation (PEF) (2016). Annual Report 2016. Lahore, Pakistan: Punjab Education Foundation. http://pef.edu.pk.pefsis.edu.pk/pdf/PEFreports/AnnualReport2016.pdf

Riboud, M. (2005). Education in Pakistan and the World Bank's Program. In Education Reform in Pakistan: Building for the future. The Woodrow Wilson International Centre for Scholars, Washington, D.C., pp.139-143.

Romero, M.J. (2015). What lies beneath? A critical assessment of PPPs and their impact on sustainable development. Brussels: Eurodad.

Rose, P., N. Singal, F. Bari, and R. Malik (2018). Identifying disability in household surveys: Evidence on education access and learning for children with disabilities in Pakistan. Research and Policy Paper 18/1. University of Cambridge, Research for Equitable Access and Learning Centre.

Rose, P. (2007). Supporting non-state providers in basic education service delivery: CREATE Pathways to Access. Research Monograph No. 4. University of Sussex, Centre for International Education.

Rosenau, P. (1999). The strengths and weaknesses of Public-Private Policy Partnerships. American Behavioral Scientist, Vol. 43, No. 1, pp.10-34.

Saporito, S. (2003). Private Choices, Public Consequences: Magnet School Choice and Segregation by Race and Poverty. Social Problems, Vol. 50, No. 2, pp.181-203.

https://doi.org/10.1525/sp.2003.50.2.181

Sikkink, D. and M.O. Emerson (2008). School choice and racial segregation in US schools: The role of parents' education. Ethnic and Racial Studies, Vol. 31, No. 2, pp.267-293.

https://doi.org/10.1080/01419870701337650

Sivasubramaniam, M. (2014). Household Educational Decision-making in Low-Fee Private Primary Schools in Kenya: An exploratory mixed methods study. Ontario Institute for Studies in Education, University of Toronto. Unpublished doctoral dissertation.

Srivastava, P. (2014). Contradictions and the persistence of the mobilizing frames of privatization: Interrogating the global evidence on low-fee private schooling. Paper presented at the annual conference of the Comparative \& International Education Society (CIES), Toronto, Ontario, Canada.

Srivastava, P. (2013). Low-fee private schooling: Issues and evidence. In P. Srivastava (ed.). Low-fee private schooling: Aggravating equity or mitigating disadvantage. Oxford, UK: Symposium Books, pp.7-35.

Srivastava, P. (2006). Private schooling and mental models about girls' schooling in India. Compare, 36(4), pp.497-514. https://doi.org/10.1080/03057920601024958

Termes, A., X. Bonal, A. Verger, and A. Zancajo (2015). Public-Private Partnerships in Colombian Education: The Equity and Quality Implications of "Colegios en concesión." London: Open Society Foundations.

Tooley, J. and P. Dixon (2006). The failures of state schooling in developing countries and the people's response. In M.A. Miles, K.R. Holmes, and M.A. O'Grady (eds). 2006 Index of Economic Freedom. New York: The Heritage Foundation and the Wall Street Journal.

UNDP (2011). Pakistan: Human Development Indicators. In Human Development Report: Sustainability and Equity: A Better Future for All. http://hdr.undp.org/sites/default/files/reports/271/hdr 2011 en complete.pdf

UNESCO (2017). A guide for ensuring inclusion and equity in education. UNESCO: Paris. http://unesdoc.unesco.org/images/0024/002482/248254e.pdf 
UNESCO (2015). Education 2030: Incheon Declaration and Framework for Action for the implementation of SDG4. http://uis.unesco.org/sites/default/files/documents/education-2030-incheonframework-for-action-implementation-of-sdg4-2016-en 2.pdf

UNICEF (2015). Global Initiative on Out-of-School Children. UNESCO: New York. http://allinschool.org/wp-content/uploads/2015/12/F UNICEF1017 OOSCl manual-web.pdf

United Nations Population Fund (UNFPA) (2012). Marrying Too Young: End Child Marriage. UNFPA, New York. http://www.unfpa.org/sites/default/files/pub-pdf/MarryingTooYoung.pdf

Valenzuela, J.P., C. Bellei, and D. De Los Ríos (2014). Socioeconomic school segregation in a market-oriented educational system. The case of Chile. Journal of Education Policy, Vol. 29, No. 2, pp.217-241. https://doi.org/10.1080/02680939.2013.806995

Van Thiel, S. and F.L. Leeuw (2002). The performance paradox in the public sector. Public Performance and Management Review, 25(3), 267-281. https://doi.org/10.2307/3381236

Van Zanten, A. (2009). Competitive arenas and schools' logics of action: A European comparison. Compare: A Journal of Comparative and International Education, Vol. 39, No. 1, pp.85-98. https://doi.org/10.1080/03057920802447867

Verger, A. (2012). Framing and selling global education policy: the promotion of public-private partnerships for education in low-income contexts. Journal of Education Policy, Vol. 27, No. 1, pp.109-130. https://doi.org/10.1080/02680939.2011.623242

Verger. A., C. Fontdevila, and A. Zancajo (2018). Constructing Low-Fee Private Schools as an Educational Model for the Global South: From Local Origins to Transnational Dynamics. In A. Verger, M. Novelli, and H.K. Altinyelken (eds). Global Education Policy and International Development: New Agendas, Issues and Policies (2nd edition). London: Bloomsbury, pp.255-276.

Verger, A. and M. Moschetti (2017). Public-Private Partnerships as an Education Policy Approach: Multiple Meanings, Risks and Challenges. Education Research and Foresight Series, No. 19. Paris, UNESCO. https://en.unesco.org/node/268820

Verger, A. and M. Moschetti (2016). Public-Private Partnerships in Education: Exploring Different Models and Policy Options. Open Society Foundations. http://s3.amazonaws.com/ineeassets/resources/OSF-INEE PPP-roundtable Framing-paper Verger-Moschetti ePPPs (1).pdf

Verger, A., C. Fontdevila, R. Rogan, and T. Gurnet (2017). Evidence-Based Policy and the Education Privatization Debate: Analysing the Politics of Knowledge Production and Mobilization through Bibliographic Coupling. SSRN. https://ssrn.com/abstract=2898808

Waslander, S., C. Pater, and M. van der Weide (2010). Markets in Education: An Analytical Review of Empirical Research on Market Mechanisms in Education. OECD EDU Working Paper 52. https://doi.org/10.1787/5km4pskmkr27-en

Witte. J, Weimer.D, Shober, A and P, Schlomer (2007). The Performance of Charter Schools in Wisconsin. Journal of Policy Analysis and Management. Vol. 26, No. 3, pp. 557-573.

https://doi.org/10.1002/pam.20265

Wolf, P.J., B. Kisida, B. Gutmann, M. Puma, N. Eissa, and L. Rizzo (2013). School vouchers and student outcomes: Experimental evidence from Washington D.C. Journal of Policy Analysis and Management, Vol. 32, No. 2, pp.246-270. https://doi.org/10.1002/pam.21691

World Bank (2018). World Development Report 2018: Learning to Realize Education's Promise. Washington, DC: World Bank.

World Bank (2016). Third Punjab Education Sector Project. Project Appraisal Document.

World Bank (2014). What Matters Most for Engaging the Private Sector in Education: A Framework Paper. SABER Working Paper Series, Number 8.

World Bank (2012a). Second Punjab Education Sector Project. Project Appraisal Document. 
World Bank (2012b). Pakistan: Increasing Access and Quality through Education Reforms in Punjab. http://documents.worldbank.org/curated/en/214691468185038197/Pakistan-Increasing-access-andquality-through-education-reforms-in-Punjab

World Bank (2012c). Pakistan: Can Low-Cost Private Schools Improve Learning? From Evidence to Policy.

World Bank (2009). Punjab Education Sector Project. Project Appraisal Document. 


\section{ENDNOTES}

1 Pakistan Economic Survey (2018). Pakistan Economic Survey 2017-18. Islamabad: Ministry of Finance, Government of Pakistan. http://www.finance.gov.pk/survey/chapters 18/10-Education.pdf

2 Source: World Bank Education Projects Database. http://datatopics.worldbank.org/education/wQueries/qprojects

3 World Bank (2016). Third Punjab Education Sector Project. Project Appraisal Document.

4 This cost can be avoided if students live within walking distance of a school, which for many students is indeed the case. However, in some localities this was an issue and parents had to pay for transport.

5 In 2000, 164 governments committed to achieving EFA by 2015 at the World Education Forum in Dakar, Senegal. EFA means quality basic education for all young people, children and adults. See UNESCO. Education for All Movement. http://www.unesco.org/new/en/education/themes/leading-the-internationalagenda/education-for-all/ and UNESCO. (2015). Education for All 2000-2015: Achievements and Challenges. https://en.unesco.org/gem-report/report/2015/education-all-2000-2015-achievements-and-challenges

6 The Economist (2015). Learning unleashed. https://www.economist.com/news/briefing/21660063-wheregovernments-are-failing-provide-youngsters-decent-education-private-sector

7 The Economist (2018). Pakistan's lessons in school reform. https://www.economist.com/news/leaders/21734000-what-worlds-sixth-most-populous-state-can-teach-otherdeveloping-countries-pakistans-lessons

8 World Bank (2018). World Development Report 2018: Learning to Realize Education's Promise. http://www.worldbank.org/en/publication/wdr2018

9 World Bank website: World Bank Education Financing and Knowledge Activities. http://www.worldbank.org/en/topic/education/brief/world-bank-education-lending-and-non-lending-activities

10 International Finance Corporation (IFC) (2011). Education. Washington DC. http://www.sbp.org.pk/departments/ihfd/Sub-Segment Booklets/Education.pdf

11 ' $\mathrm{K}-12$ ' refers to education from kindergarten to Grade 12 , covering the age range 5-18.

12 PEF website, Mission. http://pef.edu.pk.pefsis.edu.pk/About/about-pef-mission.aspx

13 PEF website, Strategy. http://pef.edu.pk.pefsis.edu.pk/About/about-pef-strategy.aspx

14 Interview communication with World Bank official in Islamabad during fieldwork for this study.

15 PEF website, Budget. http://pef.edu.pk.pefsis.edu.pk/About/about-pef-budget.aspx

16 Exchange rate used throughout report: 1 PKR $=0.0086$ USD.

17 See: http://pef.edu.pk.pefsis.edu.pk/fas/index.aspx

18 See: http://pef.edu.pk.pefsis.edu.pk/evs/index.aspx

19 See: http://pef.edu.pk.pefsis.edu.pk/nsp/index.aspx

20 S.A. Khan (2017). Why Punjab is outsourcing its public schools. Herald. https://herald.dawn.com/news/1153868.

21 J. Iqbal (2017). Govt to outsource thousands of schools. The Nation. http://nation.com.pk/02-Jul-2017/govt-tooutsource-thousands-of-schools. The numbers quoted in this article are supported by interviews with stakeholders, including DFID and World Bank country team staff, although some, including PEF, sometimes quote this figure as 4,500 schools.

22 J. Iqbal (2017) http://nation.com.pk/02-Jul-2017/govt-to-outsource-thousands-of-schools. This number was also reaffirmed in interviews with stakeholders including DFID and World Bank country team staff. Some including PEF sometimes quote this figure as 4500 schools.

23 Interview with school principal, School No. 1.

24 Interview with school principal, School No. 7.

25 Interview with school principal, School No. 13.

26 Interview with school principal, School No. 26.

27 Based on data from the government's Household Integrated Economic Survey (HIES) 2013-14, the poverty headcount ratio is 29.5 percent of the population. In monetary terms, the poverty line is set at PKR 3,030 per adult equivalent per month, giving a figure of PKR 36,360 per year.

28 This cost can be avoided if students live within walking distance of a school, which for many students is indeed the case. However, in some localities this was an issue and parents had to pay for transport.

29 Interview with school principal, School No. 4.

30 Interview with school principal, School No. 23. 
31 Interview with school principal, School No. 22. 32 Interview with school principal, School No. 26. 33 Interview with school principal, School No. 7. 34 Interview with school principal, School No. 23. 35 Interview with school principal, School No. 1. 36 Interview with school principal, School No. 17. 37 Interview with school principal, School No. 22. 38 Teacher, focus group discussion 2. 39 Interview with school principal, School No.17. 40 Interview with school principal, School No. 23. 41 Interview with school principal, School No. 7. 42 Interview with school principal, School No. 17. 43 Interview with a trainer, teacher training session 2, held by a CSO. 44 Interview with school principal, School No. 23. 45 Interview with school principal, School No. 1. 46 Interview with school principal, School No. 26. 47 Interview with school principal, School No. 11. 48 Interview with school principal, School No. 11. 49 Interview with teacher, School No. 18.

50 Interview with teacher, School No. 20.

51 Interview with school principal, School No. 19.

52 Interview with school principal, School No. 23.

53 Interview with school principal, School No. 1.

54 Interview with school principal, School No. 15.

55 Interview with school principal, School No. 5.

56 Interview with school principal, School No. 7.

57 Interview with school principal, School No. 25.

58 Interview with school principal, School No. 18.

59 PEF website, FAQs. http://pef.edu.pk.pefsis.edu.pk/fas/fas faq.aspx

60 Interview with school principal, School No. 21.

61 Interview with school principal, School No. 7.

62 Teacher, focus group discussion 1.

63 Interview with school principal, School No. 26.

64 Interview with school owner, School No. 13.

65 Interview with school principal, School No. 3.

66 Interview with school principal, School No. 7.

62 Global Initiative for Economic, Social and Cultural Rights (2017). UN Calls on Pakistan to regulate and assess privatisation of education. http://globalinitiative-escr.org/un-calls-on-pakistan-to-regulate-and-assessprivatisation-of-education 


\section{ACKNOWLEDGEMENTS}

\section{ABOUT THE AUTHOR}

Momina Afridi has a PhD in comparative education from the Ontario Institute of Studies in Education, University of Toronto. She is currently working as a consultant researcher on international education projects. Her doctoral research was on teachers in Low Fee Private Schools in Punjab, Pakistan. Her research interests include global governance institutions, education policy, gender and public private partnerships in education. In the past, Momina has worked with various non-profit organizations in Pakistan and Canada on development programming related to youth and gender. She holds a Masters in Development Studies from York University, Toronto.

\section{OPEN SOCIETY FOUNDATIONS}

Oxfam would like to thank the Open Society Foundations (OSF) Education Support Program for its generous support of this research. The views expressed in this report are those of the author and do not necessarily represent those of the Open Society Foundations.

Oxfam would like to acknowledge the work of Katie Malouf Bous in managing the research project and editing the report. This report would not have been possible without the support and guidance of Zeeshan Siddique, Nadia Daar, Helen Bunting, Nick Galasso, Ian McPherson and Mireille de Koning. We would also like to thank those who provided valuable comments including Francine Menashy, Marc Cohen, Rowan Harvey, Tony Baker, Milagros Lechleiter, Max Lawson, Akram Khurshid, Namalie Jayasinghe, and Maria Ron Balsera. 


\section{Oxfam Research Reports}

Oxfam Research Reports are written to share research results, to contribute to public debate and to invite feedback on development and humanitarian policy and practice. They do not necessarily reflect Oxfam policy positions. The views expressed are those of the author and not necessarily those of Oxfam.

For more information, or to comment on this report, email advocacy@oxfaminternational.org.

(C) Oxfam International August 2018

This publication is copyright but the text may be used free of charge for the purposes of advocacy, campaigning, education, and research, provided that the source is acknowledged in full. The copyright holder requests that all such use be registered with them for impact assessment purposes. For copying in any other circumstances, or for re-use in other publications, or for translation or adaptation, permission must be secured and a fee may be charged. Email policyandpractice@oxfam.org.uk

The information in this publication is correct at the time of going to press.

Published by Oxfam GB for Oxfam International under ISBN 978-1-78748-300-2 in August 2018.

DOI: $10.21201 / 2018.3002$

Oxfam GB, Oxfam House, John Smith Drive, Cowley, Oxford, OX4 2JY, UK.

\section{OXFAM}

Oxfam is an international confederation of 20 organizations networked together in more than 90 countries, as part of a global movement for change, to build a future free from the injustice of poverty. Please write to any of the agencies for further information, or visit www.oxfam.org

Oxfam America (www.oxfamamerica.org)

Oxfam Australia (www.oxfam.org.au)

Oxfam-in-Belgium (www.oxfamsol.be)

Oxfam Brasil (www.oxfam.org.br)

Oxfam Canada (www.oxfam.ca)

Oxfam France (www.oxfamfrance.org)

Oxfam Germany (www.oxfam.de)

Oxfam GB (www.oxfam.org.uk)

Oxfam Hong Kong (www.oxfam.org.hk)

Oxfam IBIS (Denmark) (http://oxfamibis.dk/)
Oxfam India (www.oxfamindia.org)

Oxfam Intermón (Spain) (www.oxfamintermon.org)

Oxfam Ireland (www.oxfamireland.org)

Oxfam Italy (www.oxfamitalia.org)

Oxfam Japan (www.oxfam.jp)

Oxfam Mexico (www.oxfammexico.org)

Oxfam New Zealand (www.oxfam.org.nz)

Oxfam Novib (Netherlands) (www.oxfamnovib.nl)

Oxfam Québec (www.oxfam.qc.ca)

Oxfam South Africa (www.oxfam.org.za) 